\title{
Steroid Metabolism in Thermophilic Actinobacterium Saccharopolyspora hirsuta VKM Ac-666 ${ }^{\mathrm{T}}$
}

\author{
Tatyana Lobastova ${ }^{1}$, Victoria Fokina ${ }^{1, *}$, Sergey Tarlachkov ${ }^{1}$, Andrey Shutov ${ }^{1}$, Eugeny Bragin ${ }^{1}$, \\ Alexey Kazantsev ${ }^{2}$ and Marina Donova ${ }^{1}$ \\ 1 G.K. Skryabin Institute of Biochemistry and Physiology of Microorganisms, Federal Research Center \\ "Pushchino Scientific Center for Biological Research of the Russian Academy of Sciences", Pr. Nauki 5, \\ 142290 Pushchino, Russia; lobastova_t@rambler.ru (T.L.); sergey@tarlachkov.ru (S.T.); \\ w__w@rambler.ru (A.S.); bragory@yandex.ru (E.B.); mv_donova@rambler.ru (M.D.) \\ 2 Chemistry Department, Lomonosov Moscow State University, Leninskie Gory 1/3, 119991 Moscow, Russia; \\ mak@org.chem.msu.ru \\ * Correspondence: 2vvfokina@gmail.com; Tel.: +7-916-321-62-94
}

Citation: Lobastova, T.; Fokina, V.; Tarlachkov, S.; Shutov, A.; Bragin, E.; Kazantsev, A.; Donova, M. Steroid Metabolism in Thermophilic Actinobacterium Saccharopolyspora hirsuta VKM Ac-666 ${ }^{\mathrm{T}}$. Microorganisms 2021, 9, 2554. https://doi.org/ 10.3390/microorganisms 9122554

Academic Editor: Peter Richard

Received: 22 November 2021 Accepted: 8 December 2021

Published: 10 December 2021

Publisher's Note: MDPI stays neutral with regard to jurisdictional claims in published maps and institutional affiliations.

Copyright: (c) 2021 by the authors. Licensee MDPI, Basel, Switzerland. This article is an open access article distributed under the terms and conditions of the Creative Commons Attribution (CC BY) license (https:// creativecommons.org/licenses/by/ $4.0 /)$.

\begin{abstract}
The application of thermophilic microorganisms opens new prospects in steroid biotechnology, but little is known to date on steroid catabolism by thermophilic strains. The thermophilic strain Saccharopolyspora hirsuta VKM Ac- $666^{\mathrm{T}}$ has been shown to convert various steroids and to fully degrade cholesterol. Cholest-4-en-3-one, cholesta-1,4-dien-3-one, 26-hydroxycholest-4-en-3-one, 3-oxo-cholest-4-en-26-oic acid, 3-oxo-cholesta-1,4-dien-26-oic acid, 26-hydroxycholesterol, 3 $\beta$-hydroxycholest-5-en-26-oic acid were identified as intermediates in cholesterol oxidation. The structures were confirmed by ${ }^{1} \mathrm{H}$ and ${ }^{13} \mathrm{C}-\mathrm{NMR}$ analyses. Aliphatic side chain hydroxylation at $\mathrm{C} 26$ and the A-ring modification at $\mathrm{C} 3$, which are putatively catalyzed by cytochrome P450 monooxygenase CYP125 and cholesterol oxidase, respectively, occur simultaneously in the strain and are followed by cascade reactions of aliphatic sidechain degradation and steroid core destruction via the known 9(10)-secopathway. The genes putatively related to the sterol and bile acid degradation pathways form three major clusters in the S. hirsuta genome. The sets of the genes include the orthologs of those involved in steroid catabolism in Mycobacterium tuberculosis H37Rv and Rhodococcus jostii RHA1 and related actinobacteria. Bioinformatics analysis of 52 publicly available genomes of thermophilic bacteria revealed only seven candidate strains that possess the key genes related to the 9(10)-seco pathway of steroid degradation, thus demonstrating that the ability to degrade steroids is not widespread among thermophilic bacteria.
\end{abstract}

Keywords: thermophilic actinobacteria; steroids; sterol catabolism; cholate; Saccharopolyspora hirsuta; bioconversion

\section{Introduction}

Steroids are abundant biomolecules in various environments and growth substrates for diverse bacteria. Sterols (e.g., cholesterol, ergosterol, and phytosterols) are steroid $3 \beta$ alcohols with an alkyl side chain consisting of 8-10 carbon atoms. Structurally, bile acids differ from sterols by cis-A/B-ring juncture, $\alpha$-orientation of hydroxyl at C 3 , a saturated steroid core, and a C5 acyl side chain. Due to the unique lipophilic/amphiphilic properties, steroidal compounds play vital functions in all living organisms. Annually large amounts of sterols, bile acids, and other steroids enter into the environment via the decay of biomass or excretion by humans and animals and as industrial wastes of steroid production plants.

Modern bioinformatics studies of publicly available genomes/metagenomes have highlighted the global distribution of actinobacteria capable of sterol and cholate degradation from various ecological niches (soil, aquatic environments, waste, etc.) [1,2]. Currently, the so-called 9(10)-seco-steroid pathway is the only one known for sterol and cholate aerobic degradation by actinobacteria [3-6]. This pathway has been intensively studied in the 
pathogenic species M. tuberculosis [7] and Rhodococcus strains [8,9] and the non-pathogenic species Mycolicibacterium smegmatis $\mathrm{mc}^{2} 155$ [10], Gordonia cholesterolivorans [11], and Nocardioides simplex [12]. Aerobic cholate degradation has been mainly studied for Rhodococcus strains (e.g., R. jostii RHA1) [13] and Pseudomonas stutzeri Chol1 [14], Pseudomonas putida DOC21 [15], and Comamonas testosteroni TA441 [16]. In general, the molecular mechanisms of steroid catabolism have been studied mainly for mesophilic actinobacteria, while little is known about the features of thermophilic actinobacteria capable of steroid oxidation.

Thermophilic microorganisms and their enzymes are widely used in the production of foods and detergents and the pulp and paper, textile, and mining industries [17]. An impressive example is provided by Taq polymerase (named after Thermus aquaticus), which is indispensable for PCR techniques in medicine and biology [18]. Application of thermophilic strains for steroid bioconversion is of great importance since it may provide economically feasible biotechnologies by decreasing the production costs for bioreactor cooling, especially in countries with hot climate. Besides, higher steroid solubility at elevated temperatures is favorable for steroid bioconversion performance. However, data on steroid bioconversion by thermophilic bacteria are scarce and pertain mainly to distinct reactions, such as progesterone conversion by Bacillus thermoglucosidasius (=Parageobacillus thermoglucosidasius) [19] and Geobacillus kaustophilus [20] and reduction of the 3-keto group as well as the $\Delta^{4}$-double bond in various steroid ketones by the extremely thermophilic bacterium Calderiella acidophila [21].

The moderately thermophilic Saccharopolyspora hirsuta VKM Ac- $666^{\mathrm{T}}$ [22] is capable of transforming various steroids, such as lithocholic acid (LCA) [23], dehydroepiandrosterone, androstenedione, and $3 \beta, 7(\alpha / \beta)$-dihydroxy-5-ene-D-homo-lactones [24]. Recently, the Ac- $666^{\mathrm{T}}$ genome has been sequenced and preliminary annotated [25].

In this work, aerobic conversion of cholesterol and LCA by S. hirsuta VKM Ac- $666^{\mathrm{T}}$ was studied and the main intermediates were identified. The set of the genes putatively involved in sterol and cholate catabolism pathways was revealed, and their organization and clustering were examined. The presence of genes coding for key steroid degradation enzymes was estimated in the genomes of thermophilic bacteria of different taxa, and potent microbial steroid degraders that might function at elevated temperatures were predicted.

\section{Materials and Methods}

\subsection{Materials}

Cholesterol (Serva, Heidelberg, Germany), lithocholic acid (LCA) from Acros Organics (Merelbeke, Belgium), cholestenone from Maybridge (Altrincham, UK), randomly methylated $\beta$-cyclodextrin (MCD) from Wacker-Chemie GmbH (Munich, Germany), malt extract for microbiology and corn steep solids from Sigma-Aldrich (St. Louis, MO, USA), and soluble starch and yeast extract from Difco (Franklin Lakes, NJ, USA) were used. Other materials and solvents were of analytical grade and were purchased from commercial suppliers.

\subsection{Microorganism}

The strain Saccharopolyspora hirsuta VKM Ac- $666^{\mathrm{T}}$ was obtained from the All-Russian Collection of Microorganisms (VKM).

\subsection{Microorganism Cultivation and Cholesterol Conversion}

The GSMY medium [26], which contained (g/L): glucose, 7; soluble starch, 10; malt extract, 5; yeast extract, 4.5; and $\mathrm{CaCO}_{3}, 0.05$ ( $\mathrm{pH}$ 7.0-7.2), was used because its positive effect on the accumulation of intermediate products of bioconversion was shown in preliminary experiments. The strain was grown in shake flasks $(750 \mathrm{~mL})$ containing $50 \mathrm{~mL}$ of the GSMY medium aerobically $(200 \mathrm{rpm})$ at $45^{\circ} \mathrm{C}$ for $48 \mathrm{~h}$. The resulting seed culture $(5 \mathrm{~mL}$ ) was added into shake flasks containing $50 \mathrm{~mL}$ of the same medium. Each steroid (cholesterol or LCA) was added as a solution in MCD to a final concentration of $0.5 \mathrm{~g} / \mathrm{L}$ $24 \mathrm{~h}$ after inoculation. Molar ratios (steroid:MCD) were 1:5 or 1:3 for cholesterol and LCA, respectively. Bioconversion was carried out aerobically $(200 \mathrm{rpm})$ at $45^{\circ} \mathrm{C}$ for $144 \mathrm{~h}$. For 
growth estimation, the strain was incubated on GSMY agar slants at 20, 30, 37, 45, 50, 55, and $60^{\circ} \mathrm{C}$ for $24 \mathrm{~h}$.

For biomass estimation, the samples of the broth $(24 \mathrm{~h})$ were centrifuged, the residue was washed twice with distilled water, and then it was dried at $105^{\circ} \mathrm{C}$ to constant weight.

The experiments were performed in triplicate.

\subsection{Steroid Metabolite Isolation and Identification}

After 48 and $144 \mathrm{~h}$ of cholesterol conversion, steroids were extracted from the supernatant $(\sim 500 \mathrm{~mL} ; 8000 \times g, 30 \mathrm{~min})$ with ethyl acetate $(250 \mathrm{~mL})$ three times and the pooled organic extract was concentrated on a rotary evaporator. Crude residues (25-30 mg) were applied on preparative thin layer chromatography (TLC) plates (ALUGRAM SIL G-200 UV254, Macherey-Nagel, Düren, Germany) and developed in benzene:acetone (4:1,v/v). Individual compounds were eluted with ethyl acetate and evaporated to dryness. Chromatographic purity of the compounds was controlled by TLC and HPLC. Lithocholic acid bioconversion metabolites formed in small amounts and were not isolated and identified because their accumulation was insufficient.

\subsection{Thin Layer Chromatography (TLC)}

Samples of cultivation broth $(1 \mathrm{~mL})$ were taken every $24 \mathrm{~h}$ and extracted with $2 \mathrm{~mL}$ of ethyl acetate. The extracts were applied on TLC plates (ALUGRAM SIL G/UV254, Germany) and developed in benzene:acetone $(4: 1, v / v)$ and $\mathrm{CHCl}_{3}$ :acetone: $\mathrm{CH}_{3} \mathrm{COOH}$ $(50: 50: 0.5, v / v / v)$ for cholesterol and LCA bioconversion derivatives, respectively. Steroids with the 3-oxo-4-ene moiety were visualized under UV light (254 nm) using a hemiscope CN-15MC UV Darkroom (Vilber Lourmat, Collégien, France). To visualize cholesterol and its derivatives with the $3 \beta$-ol-5-ene configuration, the TLC plates were treated with $4 \%(w / v)$ phosphomolybdic acid hydrate solution in ethyl alcohol, followed by heating at 60-65 ${ }^{\circ} \mathrm{C}$. LCA and its derivatives were assayed after staining the TLC plates with a $\mathrm{MnCl}_{2}$ solution [27] and heating at $105^{\circ} \mathrm{C}$ for 5-10 min and visualized under UV light (365 nm).

\subsection{High-Performance Liquid Chromatography (HPLC)}

HPLC analyses were performed using reversed-phase HPLC on an Agilent Infinity 1200 system (Agilent Technologies, Germany SA) with a Symmetry column $(250 \times 4.6 \mathrm{~mm}$, $5 \mu \mathrm{m})$ with a Symmetry C18 precolumn $(5 \mu \mathrm{m}, 3.9 \times 20 \mathrm{~mm})$ (Waters, Milford, MA, USA) at $50^{\circ} \mathrm{C}$ and a flow rate of $1 \mathrm{~mL} / \mathrm{min}$. Steroid assays were performed using two mobile phases (acetonitrile:water:acetic acid (60:40:0.01, v/v/v) and acetonitrile:2-propanol:water (50:45:5, $v / v / v)$ ) with UV-detection at $200 \mathrm{~nm}$ (for compounds with the $3 \beta$-ol-5-ene configuration) and $240 \mathrm{~nm}$ (for compounds with the 3-oxo-4-ene configuration).

2.7. Mass-Spectrometry (MS), ${ }^{1} \mathrm{H}$ - and ${ }^{13} \mathrm{C}$-Nuclear Magnetic Resonance Spectroscopy $\left({ }^{1} \mathrm{H}\right.$ - and ${ }^{13}$ C-NMR Spectroscopy)

MS spectra of compounds II, III, and IV were recorded on a tandem mass spectrometer LCQ Advantage MAX (Thermo Finnigan, Waltham, MA, USA) in the positive ion [M + $\mathrm{H}]^{+}$mode at an evaporator temperature of $350{ }^{\circ} \mathrm{C}$ and capillary temperature of $170{ }^{\circ} \mathrm{C}$. MS/MS spectra were obtained using normalized collision energy (Normolized Collision Energy ${ }^{\mathrm{TM}}$ ) ranging from $20 \%$ to $40 \%$. Data were collected and processed using the Xcalibur software. HRMS experiments for compounds V, VI, VII, and VIII were performed with an Orbitrap Elite mass spectrometer (Thermo Fisher Scientific GmbH, Bremen, Germany) with an ESI source.

${ }^{1} \mathrm{H}$ - and ${ }^{13} \mathrm{C}-\mathrm{NMR}$ spectra were recorded at 400 and $100.6 \mathrm{MHz}$, respectively, with a Bruker Avance 400 spectrometer. Chemical shifts were measured relative to the solvent signal. Only characteristic signals are given in ${ }^{1} \mathrm{H}-\mathrm{NMR}$ of steroids. 


\subsection{Genome Analysis}

Annotation of the genome was carried out using NCBI PGAP [28], RAST (http:/ / rast. nmpdr.org/, accessed on 10 September 2019) [29,30] and KAAS (https:/ /www.genome.jp/ tools/kaas/, accessed on 10 September 2019) [31]. Orthologous and paralogous relations between genes of the S. hirsuta VKM Ac- $666^{\mathrm{T}}$, Mycobacterium tuberculosis $\mathrm{H} 37 \mathrm{Rv}$ and Rhodococcus jostii RHA1 genomes were found using OrthoFinder 2.5.1 [32,33] with inflation parameter 1.5. A BLAST search [34] against non-redundant protein sequences (NCBI database) was used as an additional tool to confirm the predetermined enzyme function. Reciprocal BLAST was used in several cases to search for the genes that correspond to the known steroid catabolism genes one-to-one.

\subsection{Phylogenetic Analysis}

A phylogenetic dendrogram showing the relationships of KstD homologs was constructed by the maximum likelihood algorithm in MEGA7 [35]; the sequences were aligned with MUSCLE. Default parameters were used in all cases.

\subsection{BLAST Search for Steroid Catabolism Genes}

Search for the key genes of the steroid catabolic 9,10-seco-pathway $(k s t D, k s h A$, and $k s h B$ ) was carried out against several dozen available genomes of thermophilic strains, using the BLAST+ program [36]. The protein sequences of KstD (NP_218054.1), KshA (NP_218043.1), and KshB (NP_218088.1) of M. tuberculosis H37Rv were used as reference ones. A list of bacteria to be screened (Supplementary Table S1) was compiled on the basis of the literature data [37] on thermophilic and thermotolerant actinobacteria with known complete genome sequences or annotated contigs and available sources on other known thermophilic bacteria of diverse phylogenetic positions.

The genomes of Geobacillus kaustophilus and Parageobacillus thermoglucosidasius strains capable of performing some modifications of steroid compounds were screened for the steroid catabolism genes (Supplementary Table S2) using the BLAST+ program [36].

\section{Results}

\subsection{Cholesterol and Lithocholic Acid Bioconversion}

The S. hirsuta strain grew poorly at $20^{\circ} \mathrm{C}$, showed moderate growth at $30-37^{\circ} \mathrm{C}$, and grew well at $45-50{ }^{\circ} \mathrm{C}$, but slower growth was observed at $55^{\circ} \mathrm{C}$ (Figure 1).

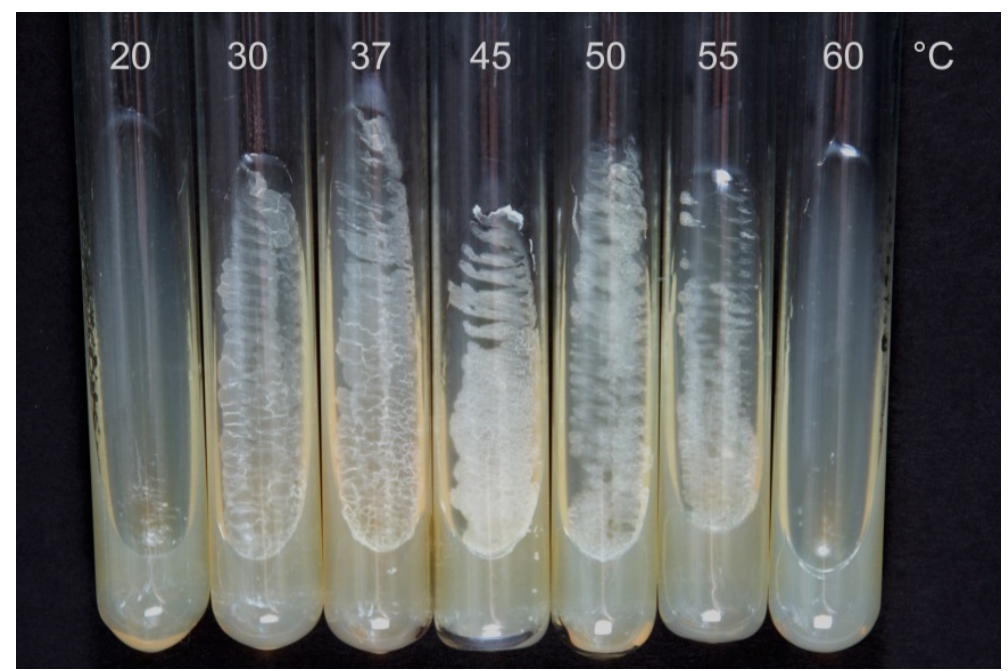

Figure 1. S. hirsuta growth at $20-60{ }^{\circ} \mathrm{C}$ for $24 \mathrm{~h}$.

The culture of $S$. hirsuta forms clumps during the growth making it difficult to assess growth using OD. The Table 1 shows dried biomass depending on the cultivation temperature. Further experiments were performed at a temperature of $45^{\circ} \mathrm{C}$. 
Table 1. Effect of temperature on the growth of S. hirsuta VKM Ac- $666^{\mathrm{T}}$.

\begin{tabular}{cccccccc}
\hline & \multicolumn{7}{c}{ Cultivation Temperature, ${ }^{\circ} \mathbf{C}$} \\
\cline { 2 - 8 } & $\mathbf{2 0}$ & $\mathbf{3 0}$ & $\mathbf{3 7}$ & $\mathbf{4 5}$ & $\mathbf{5 0}$ & $\mathbf{5 5}$ & $\mathbf{6 0}$ \\
\hline $\begin{array}{c}\text { Dried biomass * } \\
\text { g/L }\end{array}$ & $0.12 \pm 0.01$ & $0.36 \pm 0.07$ & $1.21 \pm 0.12$ & $1.86 \pm 0.21$ & $1.73 \pm 0.19$ & $0.28 \pm 0.08$ & 0 \\
\hline
\end{tabular}

* The duration of the growth-24h.

As shown in Figure 2, S. hirsuta fully transformed cholesterol within $144 \mathrm{~h}$. Intermediates were isolated, and their structures were characterized by HPLC, mass spectrometry, and ${ }^{1} \mathrm{H}$ - and ${ }^{13} \mathrm{C}-\mathrm{NMR}$-spectroscopy (Table 2, Supplementary Figures S1-S30). The intermediates were identified as 3-oxo-4-ene-compounds: cholest-4-en-3-one (II), cholesta1,4-dien-3-one (III), 26-hydroxycholest-4-en-3-one (IV), 3-oxo-cholest-4-en-26-oic acid (V),

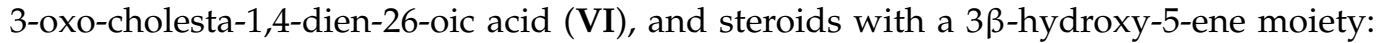
26-hydroxycholest-5-en-3 $\beta$-ol (VII) and $3 \beta$-hydroxycholest-5-en-26-oic acid (VIII).

No other steroids without a lateral chain ( $\mathrm{C}_{19}$-steroids) or a partially oxidized side chain $\left(\mathrm{C}_{22}\right.$ - or $\mathrm{C}_{24}$-steroids) were detected among the intermediates. Based on the structures and the time courses of the steroids detected, the following scheme was proposed for cholesterol bioconversion with S. hirsuta VKM Ac- $666^{\mathrm{T}}$ (Figure 3).

Among the lithocholic acid bioconversion intermediates, the compounds with both the unmodified A-ring structure and the 3-keto-4-ene moiety were found (Supplementary Figure S31A,B).

A
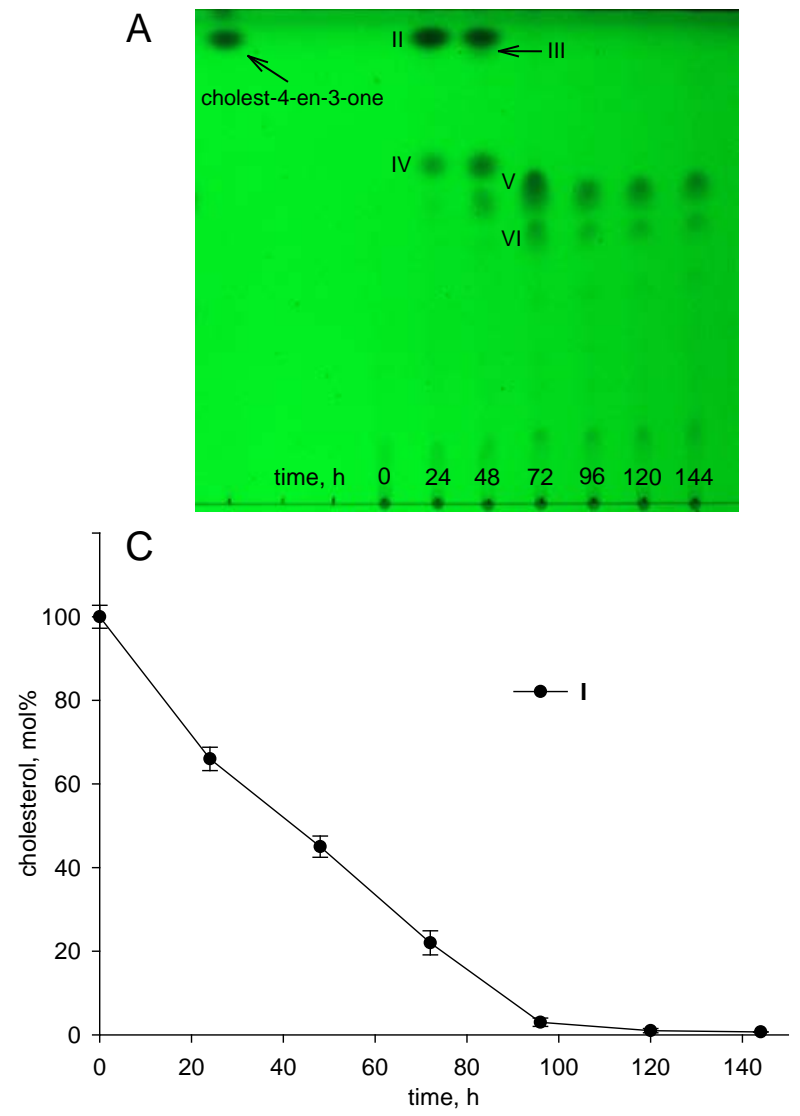

B
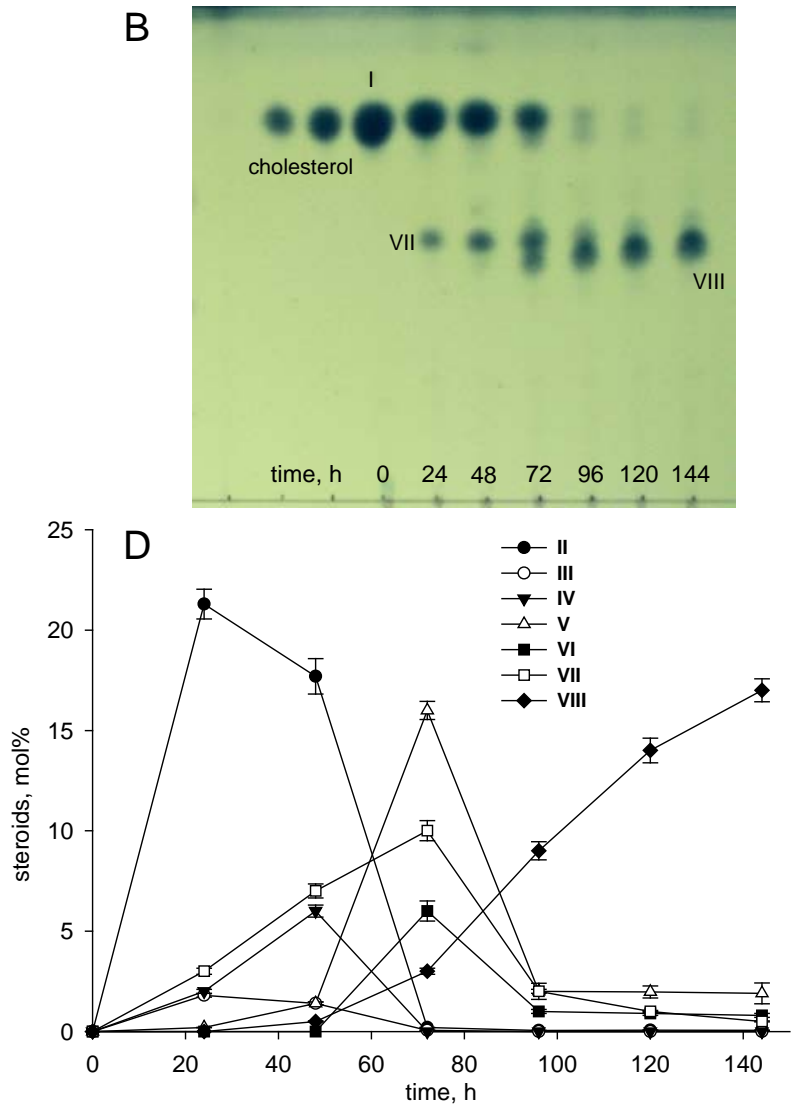

Figure 2. Cholesterol bioconversion by S. hirsuta VKM Ac- $666^{\mathrm{T}}$. Thin-layer chromatography (TLC) chromatogram of 3-keto4-ene steroids (A), visualization under ultraviolet (UV) light (254 nm), cholest-4-en-3-one as a reference compound; TLC chromatogram of $3 \beta$-hydroxycholest-5-ene steroids (B), visualization after phosphomolybdic acid staining, cholesterol as a reference compound; time course of cholesterol consumption (C); time course of the intermediates/metabolites of cholesterol bioconversion (D). The data are the averages of triplicates. I, cholesterol (cholest-5-ene-3 $\beta$-ol); II, cholest-4-en-3-one; III, cholesta-1,4-dien-3-one; IV, 26-hydroxycholest-4-en-3-one; V, 3-oxo-cholest-4-en-26-oic acid; VI, 3-oxo-cholesta-1,4-dien-26oic acid; VII, 26-hydroxycholesterol (cholest-5-ene-3 $\beta$,26-diol); VIII, 3 $\beta$-hydroxy-cholest-5-en-26-oic acid. 
Table 2. Steroid intermediates detected during cholesterol bioconversion by S. hirsuta VKM Ac- $666^{\mathrm{T}}$.

\begin{tabular}{|c|c|c|}
\hline Number & Name and Chemical Structure (mol wt) & $\begin{array}{c}\text { High-Performance Liquid Chromatography (HPLC), } \\
\text { Mass-Spectrometry (MS), }{ }^{1} \mathrm{H} \text { - and }{ }^{13} \mathrm{C} \text { - Nuclear Magnetic } \\
\text { Resonance Spectroscopy ( }{ }^{1} \mathrm{H} \text { - and }{ }^{13} \mathrm{C}-\mathrm{NMR} \text { Spectroscopy) Data }\end{array}$ \\
\hline & Cholest-4-en-3-one (384) & \\
\hline II & & $\begin{array}{l}\text { Rt (mobile phase acetonitrile:2-propanol:water 50:45:5 vol/vol/vol, } \\
\lambda 240 \mathrm{~nm} \text { ) } 8.9 \mathrm{~min} \text {; MS (intensity,\%) }[\mathrm{M}+\mathrm{H}]^{+}: 385(100), 279(5), \\
\text { 226(9), } 149(3), 109(4)\end{array}$ \\
\hline
\end{tabular}

III
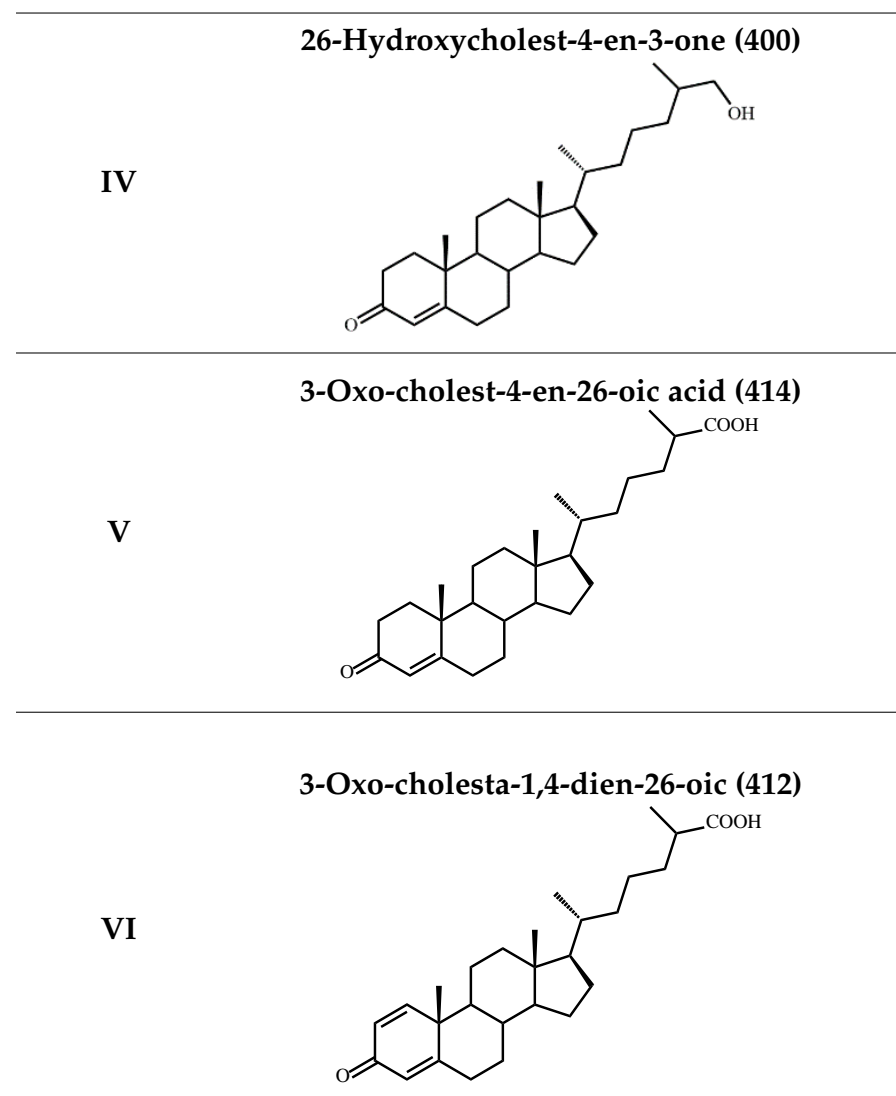

VII

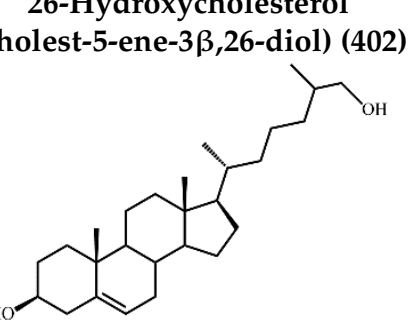

Rt (mobile phase acetonitrile:2-propanol:water 50:45:5 vol/vol/vol,

$\lambda 240 \mathrm{~nm}) 3.9 \mathrm{~min}$; Rt (mobile phase acetonitrile:water:acetic acid

(60:40:0.01 vol/vol/vol, $\lambda 240 \mathrm{~nm}) 81.8 \mathrm{~min}$; MS (intensity,\%)

$[\mathrm{M}+\mathrm{H}]^{+}$(collision energy $\left.33 \mathrm{eV}\right): 401(100), 369(33) .{ }^{1} \mathrm{H}-\mathrm{NMR}$

$\left(\mathrm{CDCl}_{3}\right) \delta: 5.73(\mathrm{~s}, 1 \mathrm{H}, \mathrm{H}-4), 1.18\left(\mathrm{~s}, 3 \mathrm{H}, 19-\mathrm{CH}_{3}\right), 0.92(\mathrm{~d}, J=6.7 \mathrm{~Hz}$, $\left.3 \mathrm{H}, 21-\mathrm{CH}_{3}\right), 0.87\left(\mathrm{~d}, \mathrm{~J}=6.6 \mathrm{~Hz}, 3 \mathrm{H}, 26(27)-\mathrm{CH}_{3}\right), 0.86(\mathrm{~d}, J=6.6 \mathrm{~Hz}$, $\left.3 \mathrm{H}, 26(27)-\mathrm{CH}_{3}\right), 0.71\left(\mathrm{~s}, 3 \mathrm{H}, 18-\mathrm{CH}_{3}\right)$

Rt (mobile phase acetonitrile:2-propanol:water 50:45:5 vol/vol/vol, $\lambda 240 \mathrm{~nm}$ ) $3.7 \mathrm{~min}$; Rt (mobile phase acetonitrile:water:acetic acid (60:40:0.01 vol/vol/vol, $\lambda 240 \mathrm{~nm}) 50.9 \mathrm{~min}$; HRMS-ESI $(\mathrm{m} / \mathrm{z})$ : $[\mathrm{M}-\mathrm{H}]^{+}$calcd for $\mathrm{C}_{27} \mathrm{H}_{41} \mathrm{O}_{3} 413,3056$; found 413,3059. ${ }^{1} \mathrm{H}-\mathrm{NMR}$

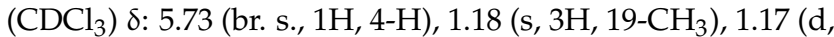
$\left.J=7.0 \mathrm{~Hz}, 3 \mathrm{H}, 27-\mathrm{CH}_{3}\right), 0.91\left(\mathrm{~d}, J=6.5 \mathrm{~Hz}, 3 \mathrm{H}, 21-\mathrm{CH}_{3}\right), 0.70(\mathrm{~s}, 3 \mathrm{H}$, 18- $\left.\mathrm{CH}_{3}\right) .{ }^{13} \mathrm{C}-\mathrm{NMR}\left(\mathrm{CDCl}_{3}\right) \delta: 199.9$ (C-3), 182.3 (C-26), 171.9 (C-5), 123.7 (C-4), 56.0, 55.8, 53.8, 42.4, 39.6, 39.2, 38.6, 35.63, 35.56, 33.92, $33.86,32.9,32.0,28.1,24.1,23.6,21.0,18.5,17.3,16.7,11.9$

Rt (mobile phase acetonitrile:2-propanol:water 50:45:5 vol/vol/vol, $\lambda 240 \mathrm{~nm}) 3.3 \mathrm{~min}$; Rt (mobile phase acetonitrile:water:acetic acid (60:40:0.01 vol/vol/vol, $\lambda 240 \mathrm{~nm}) 32.2 \mathrm{~min}$; HRMS-ESI $(\mathrm{m} / \mathrm{z})$ : $[\mathrm{M}-\mathrm{H}]^{+}$calcd for $\mathrm{C}_{27} \mathrm{H}_{39} \mathrm{O}_{3} 411,2899$; found 411, 2903. ${ }^{1} \mathrm{H}-\mathrm{NMR}$ $\left(\mathrm{CDCl}_{3}\right) \delta: 7.06(\mathrm{~d}, J=10.1 \mathrm{~Hz}, 1 \mathrm{H}, 1-\mathrm{H}), 6.24(\mathrm{dd}, J=1.9,10.1 \mathrm{~Hz}$, $1 \mathrm{H}, 2-\mathrm{H}), 6.08$ (br. s., $1 \mathrm{H} .4-\mathrm{H}), 1.23$ (s, 3H, 19- $\left.\mathrm{CH}_{3}\right), 1,17$ (d, $\left.J=7.0 \mathrm{~Hz}, 3 \mathrm{H}, 27-\mathrm{CH}_{3}\right), 0.91\left(\mathrm{~d}, J=6.5 \mathrm{~Hz}, 3 \mathrm{H}, 21-\mathrm{CH}_{3}\right), 0.73(\mathrm{~s}, 3 \mathrm{H}$, 18- $\left.\mathrm{CH}_{3}\right) .{ }^{13} \mathrm{C}-\mathrm{NMR}\left(\mathrm{CDCl}_{3}\right) \delta: 186.6(\mathrm{C}-3), 182.3(\mathrm{C}-26), 169.8(\mathrm{C}-5)$, 156.3 (C-1), 127.4 (C-2), 123.7 (C-4), 56.0, 55.4, 52.3, 43.7, 42.6, 39.4, $39.2,35.6,35.5,35.4,33.9,33.7,32.9,28.1,24.4,23.6,22.8,18.6,18.5$, $16.7,12.0$

Rt (mobile phase acetonitrile:2-propanol:water 50:45:5 vol/vol/vol, $\lambda 200 \mathrm{~nm}) 3.9 \mathrm{~min}$; Rt (mobile phase acetonitrile:water:acetic acid (60:40:0.01 vol/vol/vol, $\lambda 200 \mathrm{~nm}) 78.9 \mathrm{~min}$; HRMS-ESI $(\mathrm{m} / \mathrm{z})$ : $[\mathrm{M}-\mathrm{H}]^{+}$calcd for $\mathrm{C}_{27} \mathrm{H}_{45} \mathrm{O}_{2}$ 401,3420; found 401,3415. ${ }^{1} \mathrm{H}-\mathrm{NMR}$ $\left(\mathrm{CDCl}_{3}\right)$ 8: 5.36 (br. s., $\left.1 \mathrm{H}, 6-\mathrm{H}\right), 3.53(\mathrm{~m}, 1 \mathrm{H}, 3 \alpha-\mathrm{H}), 3.51(\mathrm{dd}, J=6.0$, $\left.10.6 \mathrm{~Hz}, 1 \mathrm{H}, \mathrm{CH}_{2} \mathrm{OH}\right), 3.43\left(\mathrm{dd}, J=6.4,10.6 \mathrm{~Hz}, 1 \mathrm{H}, \mathrm{CH}_{2} \mathrm{OH}\right), 1.01$ $\left(\mathrm{s}, 3 \mathrm{H}, 19-\mathrm{CH}_{3}\right), 0.92\left(\mathrm{~d}, J=6.5 \mathrm{~Hz}, 3 \mathrm{H}, 21-\mathrm{CH}_{3}\right), 0.91(\mathrm{~d}, J=6.7 \mathrm{~Hz}$, $\left.3 \mathrm{H}, 27-\mathrm{CH}_{3}\right), 0.68\left(\mathrm{~s}, 3 \mathrm{H}, 18-\mathrm{CH}_{3}\right) .{ }^{13} \mathrm{C}-\mathrm{NMR}\left(\mathrm{CDCl}_{3}\right) \delta: 140.8(\mathrm{C}-5)$, 121.7 (C-6), 71.8 (C-3), 68.5 (C-26), 56.8, 56.1, 50.1, 42.32, 42.28, 39.8, 37.2 , 36.5, 36.1, 35.8, 35.7, 33.5, 31.9, 31.7, 28.2, 24.3, 23.4, 21.1, 19.4, $18.7,16.5,11.9$ 
Table 2. Cont.

\begin{tabular}{|c|c|c|}
\hline Number & Name and Chemical Structure (mol wt) & $\begin{array}{c}\text { High-Performance Liquid Chromatography (HPLC), } \\
\text { Mass-Spectrometry (MS), }{ }^{1} \mathrm{H} \text { - and }{ }^{13} \mathrm{C} \text { - Nuclear Magnetic } \\
\text { Resonance Spectroscopy }\left({ }^{1} \mathrm{H} \text { - and }{ }^{13} \mathrm{C}-\mathrm{NMR} \text { Spectroscopy) Data }\right.\end{array}$ \\
\hline VIII & $3 \beta$-Hydroxy-cholest-5-en-26-oic acid (416) & 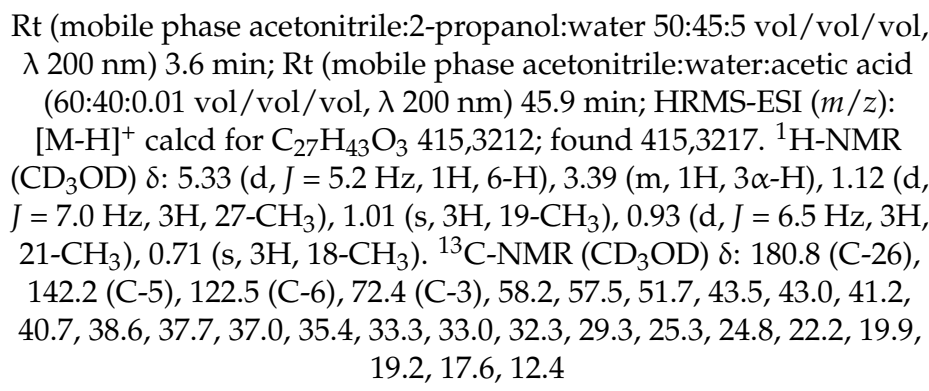 \\
\hline
\end{tabular}

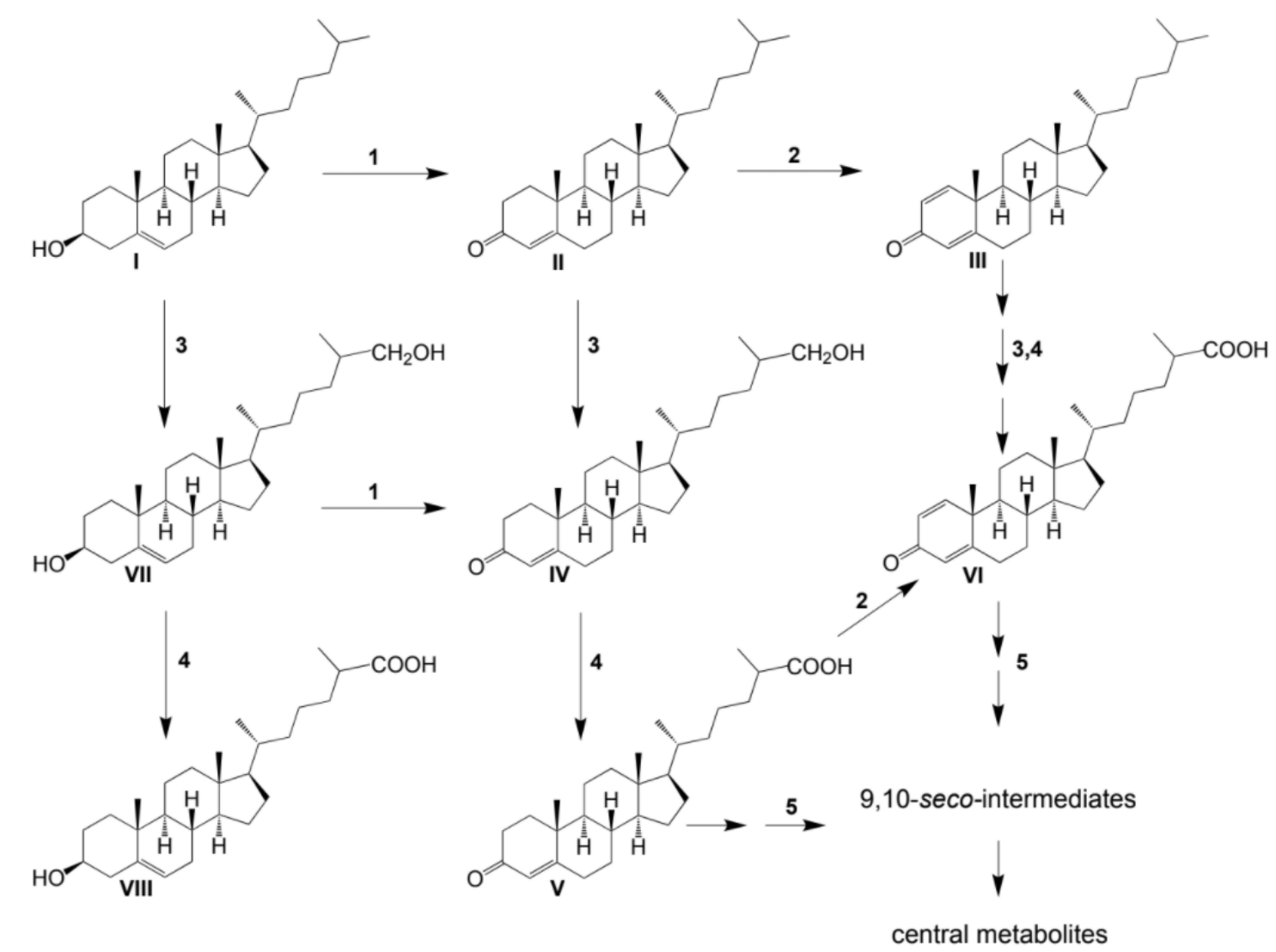

Figure 3. Scheme of cholesterol bioconversion by S. hirsuta VKM Ac-666 ${ }^{\mathrm{T}}$. Compounds: I, cholesterol; II, cholest-4-en-3-one; III, cholesta-1,4-dien-3-one; IV, 26-hydroxycholest-4-en-3-one; V, 3-oxo-cholest-4-en-26-oic acid; VI, 3-oxo-cholesta-1,4-dien26-oic acid; VII, 26-hydroxycholesterol; VIII, 3 $\beta$-hydroxycholest-5-en-26-oic acid. Biochemical reactions: 1, 3 $\beta$-hydroxyl group dehydrogenation and $\Delta^{5} \rightarrow \Delta^{4}$-isomerization; 2, 3-oxo-4-ene-steroid 1(2)-dehydrogenation; 3, C26(27)-hydroxylation; 4, C26-alcohol hydroxylation; 5 , oxidative side-chain degradation.

\subsection{General Clustering of Steroid Catabolic Gene Homologs}

When analyzing the genome of S. hirsuta (DDBJ/ENA/GenBank accession no. VWPH00000000), the genes putatively involved in steroid catabolism were mainly grouped into three clusters: cluster 1 (F1721_32550-F1721_33735), cluster 2 (F1721_00675-F1721_00760) and cluster 3 (F1721_28735-F1721_28770), and a number of genes were revealed outside the clusters (Figure 4, Supplementary Tables S3 and S4). 
Mycobacterium tuberculosis H37Rv
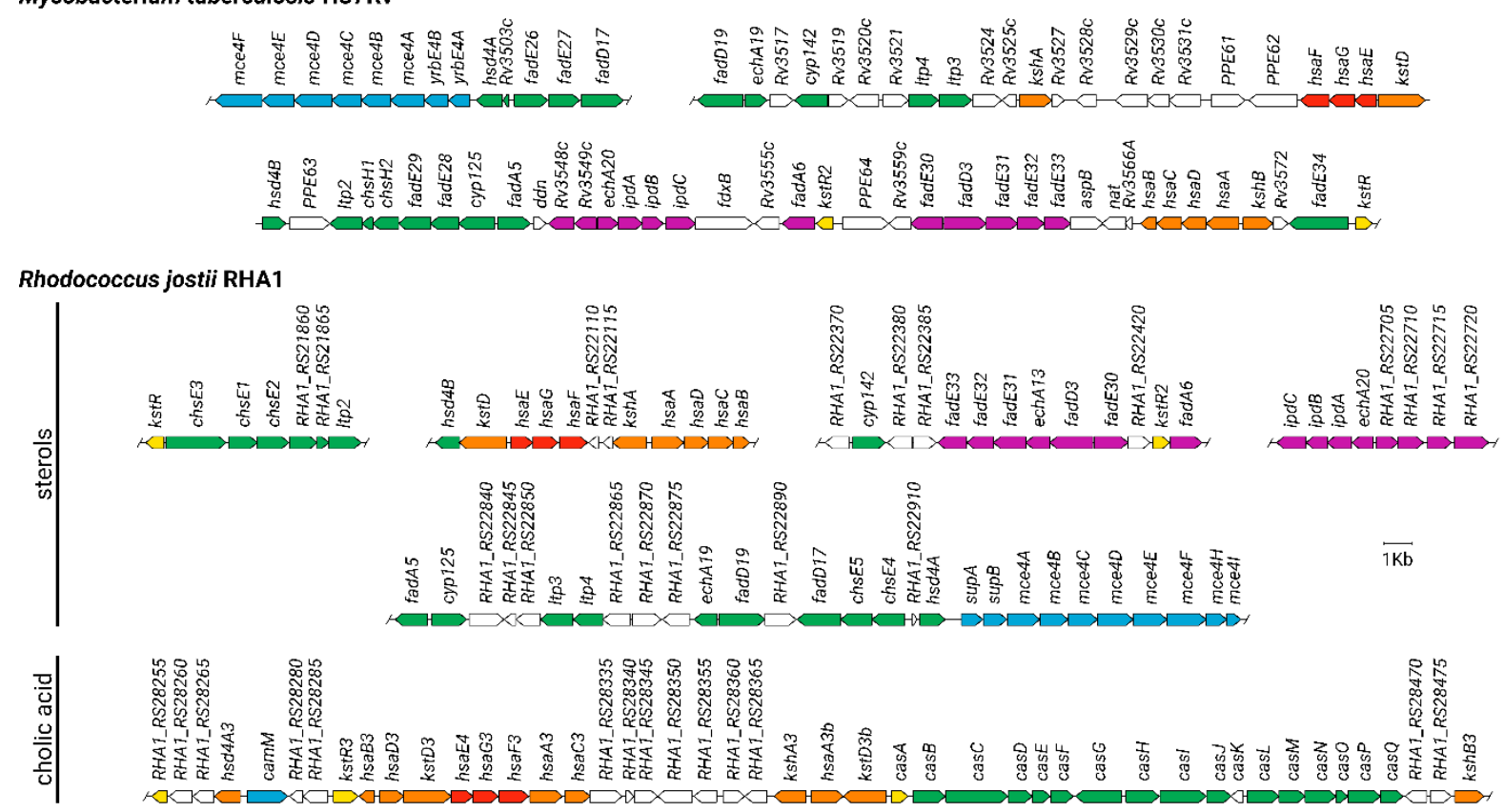

Saccharopolyspora hirsuta VKM Ac-666

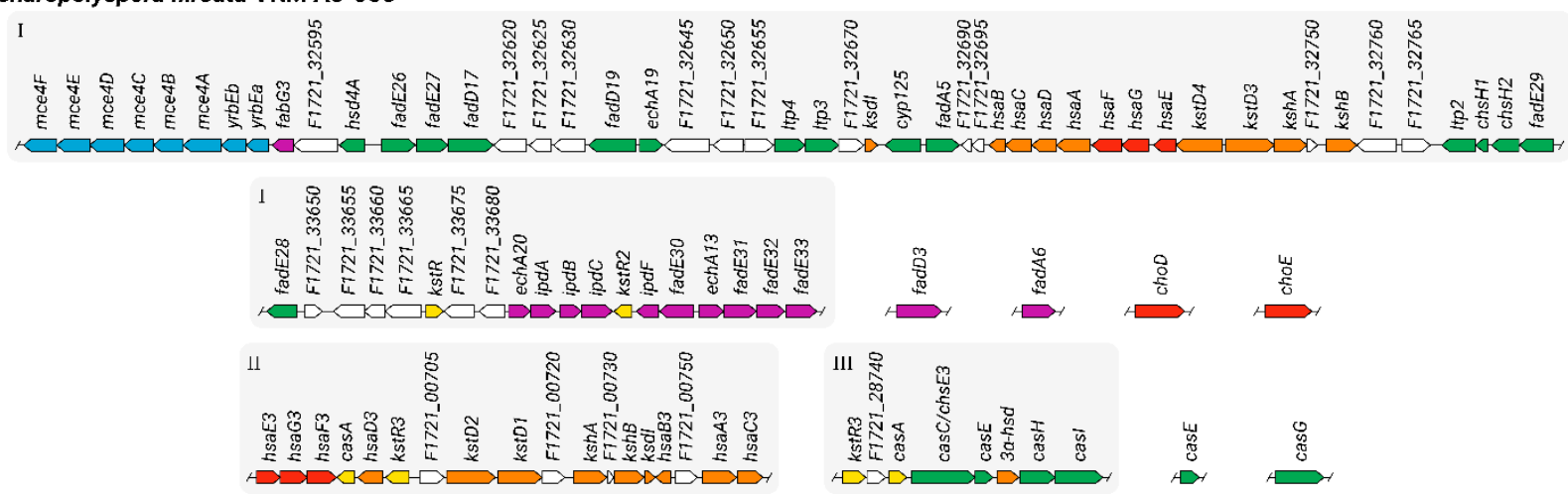

Figure 4. Organization of the S. hirsuta VKM Ac- $666^{\mathrm{T}}$ genes putatively involved in cholesterol and cholic acid catabolism. For comparison, the organization of the corresponding genes of Mycobacterium tuberculosis H37Rv and Rhodococcus jostii RHA1 [5] is shown. Genes related to cholesterol or bile acid side chain degradation are shown in green; genes related to A/B-rings degradation are shown red (cholesterol catabolism) and orange (cholic acid catabolism); genes coding for C/D-ring degradation are shown purple; blue color indicates genes coding for transport systems; regulatory elements are indicated yellow. I, II, and III are the S. hirsuta gene clusters discussed in the text.

Cluster 1 (Figure 4, Supplementary Tables S3 and S4) contains candidate genes related to a sterol side chain degradation pathway, A/B-ring oxidation, and the Mce4 system (operon mceABCDEF and the genes coding for two permease subunits $\mathrm{YrbEa}$ and $\mathrm{YrbEb}$ ). In total, four mce loci (F1721_29585-F1721_29620, F1721_32550-F1721_32585, F1721_10830F1721_10865, F1721_13950-F1721_13915) were found in S. hirsuta. The choD, choE, and fadD3 genes, presumably encoding cholesterol oxidases and HIP-CoA synthetase, respectively, were found out of the clusters in Ac- $666^{\mathrm{T}}$ (Figure 4, Supplementary Tables S3 and S4).

In Ac- $666^{\mathrm{T}}$, clusters 2 and 3 (Figure 4, Supplementary Tables S3 and S4) contain candidate genes related to the cholate degradation pathway, namely, orthologs of the $k \operatorname{sh} A$ and $k s h B$ subunit genes; two orthologs of kstDs: $k s t D 2$ and kstD1; the A/B-ring opening operon $h s a E G F$ and orthologs of $h s a D 3$ and $h s a B 3$; the $k s d I$ steroid delta-isomerase gene; $k s t R 3$ for a predicted transcriptional regulator; and orthologs of the casACEHI genes, which determine degradation of the cholate side chain. 
Figure 5 shows the scheme proposed for cholesterol bioconversion with the participation of the candidate genes of S. hirsuta VKM Ac- $666^{\mathrm{T}}$.

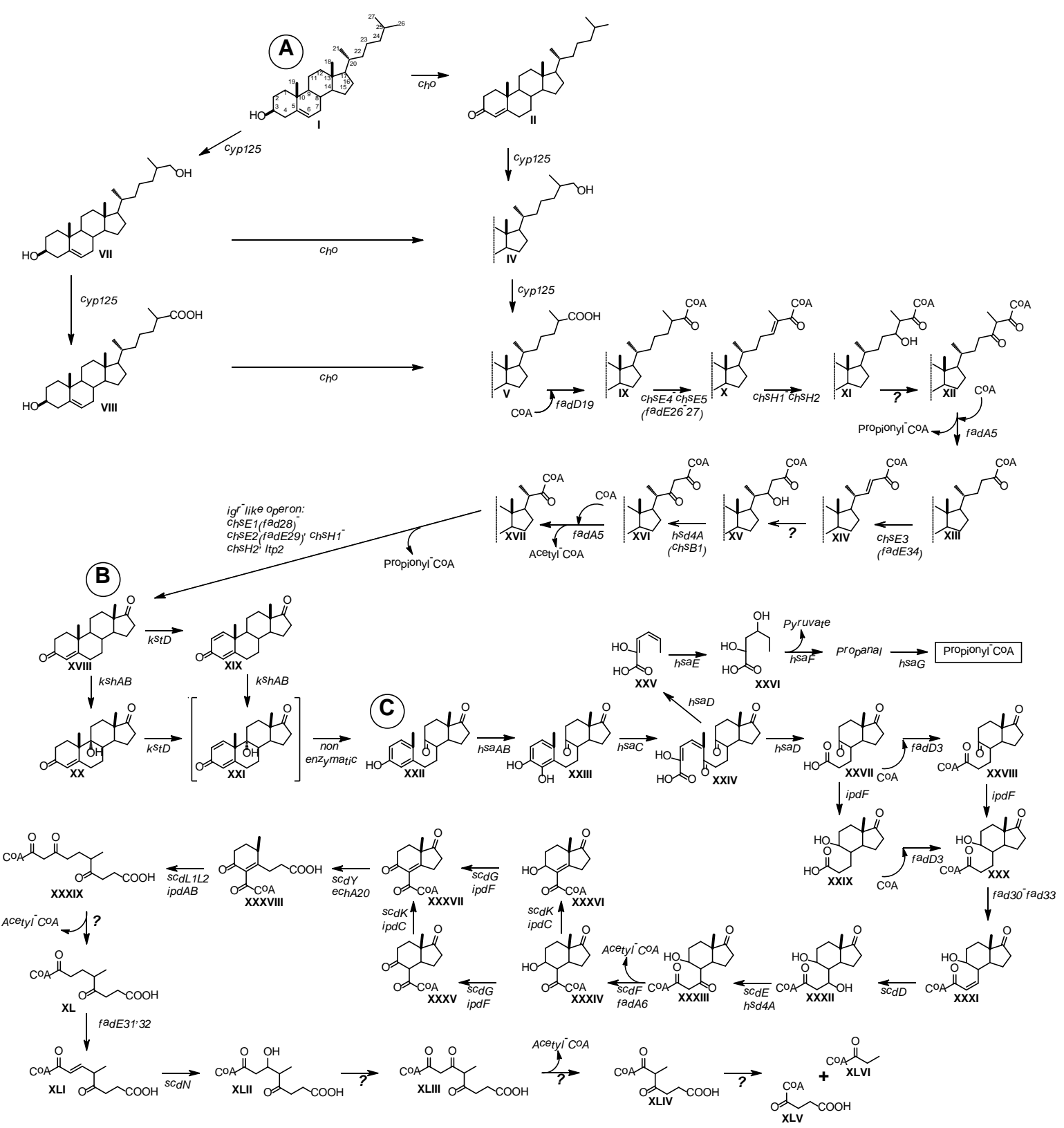

Figure 5. Biochemical scheme proposed for cholesterol catabolism in S. hirsuta VKM Ac-666 ${ }^{\mathrm{T}}$. Genes encoding respective proteins are denoted. (A) Modification of 3ß-ol-5-ene to 3-keto-4-ene moiety in the A-ring of the steroid core and degradation of the sterol side chain to $\mathrm{C}_{19}$-steroids. (B) Steroid core modifications. (C) Steroid core degradation via the 9(10)-seco pathway. I, cholesterol; II, cholest-4-en-3-one; IV, 26-hydroxy-cholest-4-en-3-one; V, 3-oxo-cholest-4-en-26-oic acid; VII, cholest-5-ene-3 $\beta$,26-diol; VIII, 3 $\beta$-hydroxy-cholest-5-en-26-oic acid; IX, 3-oxo-cholest-4-en-26-oyl-CoA; X, 3-oxo-cholesta-4,24dien-26-oyl-CoA; XI, 24-hydroxy-3-oxo-cholest-4-en-26-oyl-CoA; XII, 3,24-dioxo-cholest-4-en-26-oyl-CoA; XIII, 3-Oxo-chol-4en-24-oyl-CoA; XIV, 3-oxo-chola-4,22-dien-24-oyl-CoA; XV, 22-hydroxy-3-oxo-chol-4-en-24-oyl-CoA; XVI, 3,22-dioxo-chol-4en-24-oyl-CoA; XVII, 3-oxo-4-pregnene-20-carboxyl-CoA; XVIII, androst-4-ene-3,17-dione (AD); XIX, androsta-1,4-diene3,17-dione (ADD); XX, $9 \alpha$-hydroxy-AD; XXI, unstable $9 \alpha$-hydroxy-ADD; XXII, 3ß-hydroxy-9,10-seco-androsta-1,3,5(10)triene-9,17-dione (3ßHSA); XXIII, 3,4-dihydroxy-9,10-secoandrosta-1,3,5(10)-triene-9,17-dione (3,4-DHSA); XXIV, 4,5-9,10diseco-3-hydroxy-5,9,17-trioxoandrosta-1(10),2-diene-4-oic acid (4,9-DSHA); XXV, 2-hydroxyhexa-2,4-dienoic acid (2-HHD); XXVI, 4-hydroxy-2-oxohexanoic acid; XXVII, 9,17-dioxo-1,2,3,4,10,19-hexanorandrostan-5-oic acid (DOHNAA) or 3a $\alpha$-H-4 $\alpha$ (3'-propanoate)-7a $\beta$-methylhexahydro-1,5-indadione (HIP); XXVIII, 9,17-dioxo-1,2,3,4,10,19-hexanorandrostan-5-oyl-CoA (HIP-CoA); XXIX, 9-hydroxy-17-oxo-1,2,3,4,10,19-hexanorandrostan-5-oic acid or 3a $\alpha$-H-4 $\alpha$ (3'-propanoate)-5 $\alpha$-hydroxy-7a $\beta$ - 
methylhexahydro-1-indanone (5-OH-HIP); XXX, 9-hydroxy-17-oxo-1,2,3,4,10,19-hexanorandrostan-5-oyl-CoA (5-OH-HIPCoA); XXXI, 9-hydroxy-17-oxo-1,2,3,4,10,19-hexanorandrost-6-ene-5-oyl-CoA (5-OH-HIPE-CoA); XXXII, 7,9-Dihydroxy17-oxo-1,2,3,4,10,19-hexanorandrostan-5-oyl-CoA; XXXIII, 9-hydroxy-7,17-dioxo-1,2,3,4,10,19-hexanorandrostan-5-oylCoA; XXXIV,-9-hydroxy-17-oxo-1,2,3,4,5,6,10,19-octa-norandrostan-7-oyl-CoA or 3a $\alpha$-H-4 $\alpha$ (carboxylCoA)-5 $\alpha$-hydroxy7aß-methylhexahydro-1-indanone (5-OH-HIC-CoA); XXXV, 9,17-dioxo- 1,2,3,4,5,6,10,19-octa-norandrostan-7-oyl-CoA; XXXVI, 9-hydroxy-17-oxo-1,2,3,4,5,6,10,19-octa-norandrost-8(14)-en-7-oyl-CoA; XXXVII, 9,17-dioxo-1,2,3,4,5,6,10,19-octanorandrost-8(14)-en-7-oyl-CoA or 7a-methyl-1,5-dioxo-2,3,5,6,7,7a-hexahydro-1H-indene-4-carboxylic acid (HIEC-CoA); XXXVIII, 9-oxo-1,2,3,4,5,6,10,19-octanor-13,17-secoandrost-8(14)-ene-7,17-dioic acid-CoA-ester or (R)-2-(2-carboxyethyl)-3methyl-6-oxocyclohex-1-ene-1- carboxyl-CoA (COCHEA-CoA); XXXIX, 6-methyl-3,7-dioxo-decane-1,10-dioic acid-CoA ester; XL, 4-methyl-5-oxo-octane-1,8-dioic acid-CoA ester; XLI, 4-methyl-5-oxo-oct-2-ene-1,8-dioic acid-CoA ester (MOODACoA); XLII, 3-hydroxy-4-methyl-5-oxo-octane-1,8-dioic acid-CoA ester; XLIII, 4-methyl-3,5-dioxo-octane-1,8-dioic acidCoA ester; XLIV, 2-methyl-3-oxo-hexane-1,6-dioic acid-CoA ester; XLV, succinyl-CoA; XLVI, propionyl-CoA. Adopted from: $[8,16,38-46]$.

\subsection{BLAST Search for the Key Enzymes of Steroid Catabolism in 52 Thermophilic/ Thermotolerant Strains}

The key steroid catabolism enzymes KstD, KshA, and KshB of M. tuberculosis H37Rv were used as reference enzymes in a BLAST search carried out against several dozen publicly available genomes of thermophilic bacteria of different phylogenetic positions (Supplementary Table S1).

Among the 52 thermophilic/thermotolerant species tested, seven actinobacterial strains were found to possess proteins of $41.6 \%$ to $64.2 \%$ similar to the M. tuberculosis H37Rv enzymes: Thermomonospora curvata DSM 43183, Amycolatopsis granulosa DSM 45669, Amycolatopsis methanolica strain 239T, Amycolatopsis thermalba strain 50.9b, Thermocatellispora tengchongensis DSM 45615, Amycolatopsis ruanii strain 49.3e, and Microbispora siamensis NBRC 104113 (Supplementary Table S5).

The genomes of two strains capable of performing some modifications of steroid compounds (i.e., 6-hydroxylation, reduction of the 17/20-keto group or 4(5)-double bond, and $\mathrm{C} 17-\mathrm{C} 20 \mathrm{C}_{3}$-side chain cleavage), Geobacillus kaustophilus and Parageobacillus thermoglucosidasius, were screened for the steroid catabolism enzymes ChoD, ChoL, Ltp3-4, Hsd4A, FadE26-30, ChsH1-2, FadD17, FadD19, EchA19, HsaA-E, KstD, KshAB, IpdAB, FadD3, and EchA20 (Supplementary Table S2). Most of the proteins were absent in these strains (Supplementary Table S6). On the other hand, enzymes with $47 \%$ and $45 \%$ similarity to the reference FadA5 were revealed in G. kaustophilus and P. thermoglucosidasius, respectively; and enzymes with $48 \%$ and $41 \%$ identity to $\mathrm{HsaF}$ and $\mathrm{HsaE}$, respectively, were identified in P. thermoglucosidasius (Supplementary Table S6).

\section{Discussion}

Several thermophilic bacterial species have been reported to carry out distinct structural modifications of steroids [19-21,47], while sterol degradation by thermophilic microorganisms has not been studied so far. As shown in this research, thermophilic S. hirsuta transformed cholesterol (Figure 1). The cholesterol degradation pathway was predicted (Figure 4) based on the time courses of the intermediates (Figure 1) and bioinformatics analysis (Figure 4). The set and the order of the genes putatively involved in steroid catabolism in S. hirsuta are similar to the clusters described for M. tuberculosis $\mathrm{H} 37 \mathrm{Rv}$ and R. jostii RHA1 [5] (Figure 4).

\subsection{Cholesterol Oxidases (ChOs)}

In many actinobacteria, the sterol degradation pathway is known to begin with the modification of 3 $\beta$-hydroxy-5-ene into the 3-keto-4-ene structure by cholesterol oxidases (ChOs) or $3 \beta$-hydroxysteroid dehydrogenases (3 $\beta$-HSDs) $[48,49]$, while cytochrome P450mediated hydroxylation at $\mathrm{C} 26(27)$ has been reported to be the initial reaction of sterol degradation in Rhodococcus strains [50,51]. As evidenced from the time course of cholesterol 
conversion by $S$. hirsuta, the initial reactions of cholesterol degradation, i.e., modification of the $3 \beta$-ol-5-ene-moiety and sterol side chain C26(27)-hydroxylation, occurred independently (Figure 1).

ChOs are most likely involved in 3ß-ol-5-ene-moiety modification in S. hirsuta since no candidate genes coding for $3 \beta$-HSDs were found in Ac-666 ${ }^{\mathrm{T}}$ [25]. Two candidate cho genes, choD F1721_14655 and choE F1721_09795, were revealed in Ac-666 ${ }^{\mathrm{T}}$. Similar to other cho in actinobacteria [51], both genes are out of the steroid catabolism clusters.

\subsection{Cyp 125}

The cleavage of the cholesterol/cholestenone side chain by actinobacteria begins with hydroxylation of the terminal methyl group catalyzed by steroid 26(27)-monooxygenase to form the corresponding 26(27)-alcohols [51]. As shown for $R$. jostii RHA1, the same enzyme accounts for further oxidation to the corresponding C26-carboxylic acids [50]. Cytochrome P450 monooxygenases encoded by cyp 125 have been isolated and characterized from $M$. tuberculosis [52] and R. jostii RHA1 [50]. Cyp125 from M. tuberculosis CDC1551 has been shown to play a role in the oxidation of 26-hydroxycholest-4-en-3-one (IV) to cholest-4-en3-one-26-oic acid (V) [53]. Cyp125, cyp142, and cyp124 have been reported to encode the enzymes that perform terminal C(26)27-hydroxylation [51].

The candidate cyp125 (F1721_32680) was identified in S. hirsuta (Supplementary Tables S1 and S2). Cyp125 could be responsible for the formation of 26-hydroxycholestenone (IV), 3-oxocholest-4-ene-26-oic acid (V), 3-oxocholesta-1,4-diene-26-oic acid (VI), 26-hydroxycholesterol (VII), and 3 $\beta$-hydroxycholest-5-ene-26-oic acid (VIII) from the corresponding precursors in Ac-666 ${ }^{\mathrm{T}}$ (Figures 2-4). Probably, this strain possesses a steroid 26(27)monooxygenase capable of oxidizing the sterol side chain regardless of the $3 \beta$-hydroxy-5ene- or 3-oxo-4-ene-structure of the A-ring. No orthologs of cyp124 or cyp142 were found in S. hirsuta.

\subsection{Side Chain Degradation}

As is well established for many actinobacteria, the aliphatic side chain of sterols is degraded by a cascade of reactions similar to the $\beta$-oxidation of fatty acids. The chsE4 (fadE26) and chsE5 (fadE27) genes of M. tuberculosis H37Rv have been shown to encode acyl-CoA dehydrogenases [42]. ChsE3 of M. tuberculosis catalyzes oxidation of 3-oxochol-4-ene-24-oil$\mathrm{CoA}$ in the second round of $\beta$-oxidation of the cholesterol side chain [42]. The orthologous genes chsE1 (F1721_33645), chsE2 (F1721_32785), chsE3 (F1721_28750), chsE4 (F1721_32605), and chsE5 (F1721_32610) were found in S. hirsuta (Supplementary Tables S3 and S4).

The phylogenetic analysis of acyl-CoA synthetases revealed four different types of acyl-CoA synthetases from $R$. jostii RHA1 and M. tuberculosis H37Rv, which are specific to the chain length of steroids [54]. FadD19 from M. tuberculosis H37Rv activates cholesterol metabolites with the C8-side chain, whilst FadD17 from H37Rv acts in the case of the C5- or longer side chains; and CasG from $R$. jostii RHA1, in the case of the cholate C5-side chain. Metabolites with the C3-side chain are activated by the steroid-22-oyl-CoA synthetase CasI during cholate oxidation by R. jostii RHA1 [54]. Orthologs of fadD19 (F1721_32635), fadD17 (F1721_32615), casG (F1721_02405), and casI (F1721_28770), which encode acyl-coenzyme A synthases, were revealed in S. hirsuta (Supplementary Tables S3 and S4). Probably, the presence of the homologous genes encoding various acyl-coenzyme A synthases in Ac-666 ${ }^{\mathrm{T}}$ contributes to the adaptation of the thermophilic microorganism in nature.

As shown for $R$. rhodochrous RG32, decomposition of the sterol C24-branched side chain is mediated by aldol lyases encoded by ltp3 and ltp4 [55]. The candidate genes ltp3 (F1721_32665) and ltp4 (F1721_32660) putatively involved in degrading sterols with branched side chains were identified in S. hirsuta (Supplementary Tables S3 and S4).

Enoyl-coenzyme A is a hydratase encoded by echA19 that acts on 3-oxo-chol-4,22diene-24-oyl-CoA [56]. The product of the hsd4A gene from M. neoaurum ATCC 25795 is a dual-function enzyme with both $17 \beta$-hydroxysteroid dehydrogenase and $\beta$-hydroxyacylCoA dehydrogenase activities [57]. Recently, it has been shown that the ChsB1 from $M$. 
tuberculosis (Rv3502c) is stereospecific and catalyzes the dehydrogenation of 22S-hydroxy3-oxo-cholest-4-en-24-oyl-CoA rather than its 22R stereoisomer [46]. The candidate genes echA19 (F1721_32640) and hsd4A (F1721_32600) were revealed in S. hirsuta (Supplementary Tables S3 and S4).

The role of thiolase FadA5 in the last cycle of cholesterol side chain $\beta$-oxidation has been demonstrated for M. tuberculosis H37Rv [58]. Orthologous fadA5 (F1721_32685) is present in S. hirsuta (Supplementary Tables S3 and S4).

In $M$. tuberculosis strains, the operon containing genes for a putative lipid transfer protein (ltp2 / Rv3540c), two MaoC-like hydratases (chsH1/Rv3541c, chsH2/Rv3542c), two acylCoA dehydrogenases (fadE29/chsE2/Rv3543c, fadE28/chsE1/Rv3544c), and cytochrome P450 (cyp125/Rv3545c) has been reported to be essential for virulence [39]. Recently, the function of Ltp2 in complex with a hydratase $\mathrm{ChsH} 2$ DUF35 was identified as an aldolase in T. curvata DSM 43183 [59]. The orthologous genes ltp2 (F1721_32770), chsH1 (F1721_32775), and chsH2 (F1721_32780) were found in S. hirsuta (Supplementary Tables S3 and S4).

\subsection{Steroid Nucleus Degradation}

The key reactions in steroid core degradation are 1(2)-dehydrogenation and $9 \alpha$ hydroxylation [4]. 1(2)-Dehydrogenation is catalyzed by 3-ketosteroid $\Delta^{1}$-dehydrogenases (KstDs) [60]. The presence of several KstDs with distinct activities has been reported for actinobacterial species [60-65]. Three putative KstDs were identified in Ac-666 ${ }^{\mathrm{T}}$ (Supplementary Tables S3 and S4). The candidate gene kstD3 is in cluster 1 (Figure 4). The two other candidate $k s t D s, k s t D 2$ and $k s t D 1$, are located side by side in cluster 2 (Figure 4). As reported earlier, S. hirsuta efficiently transforms androst-4-ene-3,17-dione (AD), $3 \beta$ hydroxy-5-en-17-one (DHEA), and $3 \beta, 7(\alpha / \beta)$-dihydroxy-5-ene-D-homo-lactones into the corresponding 1(2)-dehydrogenated derivatives, thus evidencing high KstD activity [24].

In the present study, detection of the intermediates with a 3-keto-1,4-diene structure, such as cholesta-1,4-dien-3-one (III) and 3-oxo-cholesta-1,4-diene-26-oic acid (VI), evidenced that 1(2)-dehydrogenation can take place at the early stages of sterol catabolism in S. hirsuta (Figure 2). As shown for M. neoaurum DSM 1381, KstD1, KstD2, and KstD3 catalyze 1(2)-dehydrogenation of various steroid substrates at different stages of sterol degradation [65]. The presence of several KstDs probably provides 1(2)-dehydrogenation of various steroids in S. hirsuta.

The phylogenetic dendrogram with the KstD homologs demonstrates that KstD2 from S. hirsuta is in close identity with KstD2 from N. simplex (= Pimelobacter simplex) (AIY19529.1) (Figure 6). KstD from M. tuberculosis is in the same clade with KstD3 from S. hirsuta, while KstD1 from S. hirsuta is more similar to the corresponding enzymes of N. simplex (Figure 6).

$9 \alpha$-Hydroxylation is carried out by 3-ketosteroid $9 \alpha$-hydroxylase KshAB, which consists of an oxygenase component (KshA) and a reductase component (KshB) [66]. Five different paralogous genes have been reported to encode the KshA subunits in Mycolicibacterium fortuitum VKM Ac-1817D (=Mycobacterium sp. VKM Ac-1817D) [61], thus providing for $9 \alpha$-hydroxylation of steroid metabolites at various stages of sitosterol catabolism [67]. Several KshAs with different substrate specificities have similarly been found in $R$. rhodochrous DSM 43269: KshA1 was shown to participate only in the cholic acid catabolism, while KshA5 could hydroxylate several substrates [68]. Two kshA orthologs (F1721_32745 and F1721_00725) and two kshB orthologs (F1721_32755 and F1721_00735) were revealed in S. hirsuta (Figure 4, Supplementary Tables S3 and S4). Most likely, these two KshABs might differ on their substrate specificity in Ac-666 ${ }^{\mathrm{T}}$.

It should be noted that no $\mathrm{C}_{19}$-steroid intermediates, such as androstenedione, androstadienedione, testosterone, or 1(2)-dehydrotestosterone, were detected during the cholesterol transformation by S. hirsuta. This could be explained either by their rapid degradation to concentrations below the detection level, or by disruption of the A/B-rings in intermediates with a preserved side chain. For instance, 9,10-seco-steroid intermediates with partially degraded side chains form during bile acid transformation with 
Rhodococcus strains, evidencing that side chain degradation and B-ring opening occur simultaneously $[69,70]$.

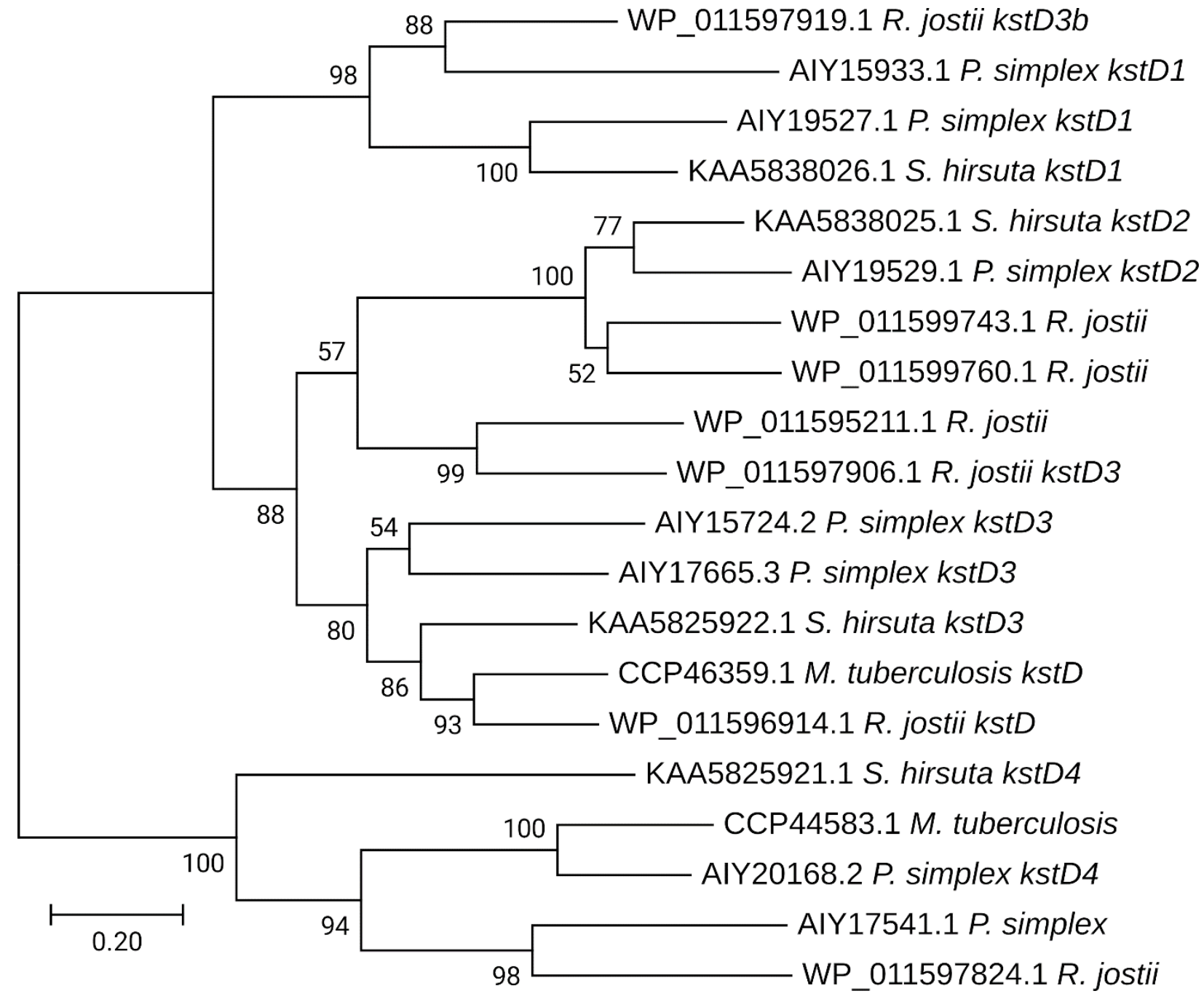

Figure 6. Dendrogram showing the phylogeny of KstD homologs. The tree was drawn to scale, with branch lengths measured in substitutions per site. Bootstrap values (based on 1000 replications) are indicated at the branch points.

\subsection{Steroid Core Degradation}

The next step of steroid core destruction is hydroxylation of 3-hydroxy-9,10-secoandrost-1,3,5(10)-triene-9,17-dione at $\mathrm{C} 4$ by flavin-dependent monooxygenase (HsaAB), resulting in a 3,4-dihydroxy-derivative [71]. The characterization of $\mathrm{HsaAB}$ was performed for the monooxygenase from $M$. tuberculosis [72]. The operon hsaBCDAFGE F1721_32700F1721_32730 presumably involved in degrading the A-ring fragments was identified in S. hirsuta (Supplementary Tables S3 and S4). The candidate genes hsaA3 (F1721_00755), hsaB3 (F1721_00745), hsaC3 (F1721_00760), and hsaD3 (F1721_00695), which are orthologous to the $R$. jostii RHA1 hsaA3B3C3D3 genes, were found in Ac- $666^{\mathrm{T}}$ (Figure 4, Supplementary Tables S3 and S4). The candidate genes $h s a F$ and $h s a G$ encode HsaF and HsaG, which putatively participate in the final stages of A-ring degradation (Supplementary Tables S3 and S4).

Degradation of the C/D-rings begins with the action of FadD3, whose physiological role has been studied in M. tuberculosis [41]. Unlike in M. tuberculosis H37Rv and R. jostii RHA1, in which fadD3 encoding HIP-CoA synthetase lies in the corresponding cluster, the ortholog of fadD3 is out of the clusters in S. hirsuta (Figure 4).

IpdE1(FadE30) and IpdE2 (FadE33) of M. tuberculosis have been shown to form a complex that catalyze the dehydrogenation of 5-OH-HIP-CoA to 5-OH-HIPE-CoA [44]. 
Crotonase Ech20 is responsible for the hydrolytic C-ring cleavage to yield HIEC-CoA. IpdAB hydrolytically cleaves the $\mathrm{C}$-ring in the substrate COCHEA-CoA [43]. The candidate genes ipdAB (F1721_33690-F1721_33695), ipdC (F1721_33700), fadE30 (F1721_33715), fadE33 (F1721_33735) and echA20 (F1721_33685) (cluster 1) are presumably involved in C/D-ring degradation in S. hirsuta (Figure 4, Supplementary Tables S3 and S4).

The product of the opening of both of the C/D-rings is transformed by putative thiolase FadA6 to yield acetyl-CoA and 4-methyl-5-oxo-octanedioyl-CoA [5]. The last intermediate undergoes $\beta$-oxidation by acyl-CoA dehydrogenase FadE32 or the Fad31FadE32 complex in Mycobacterium [43]. Finally, the $\beta$-oxidation products acetyl-CoA and 2 -methyl- $\beta$-ketoadipyl-CoA are released, followed by the formation of propionyl-CoA and succinyl-CoA [5]. The orthologs of fadE31 (F1721_33725) and fadE32 (F1721_33730) were detected in S. hirsuta (Figure 4, Supplementary Tables S3 and S4).

\subsection{Search for the Key Genes of Steroid Catabolism in the Genomes of Thermophilic/ Thermotolerant Bacteria}

In order to find out whether steroid degraders are widespread among thermophilic bacteria, a BLAST search for the kstD and kshAB key genes of the steroid catabolic 9,10-secopathway was performed using 52 publicly available genomes of thermophilic/ thermotolerant strains (Supplementary Table S1). Only seven actinobacterial strains were identified as putative steroid degraders (Supplementary Table S5). The other thermophilic/thermotolerant strains do not contain enzymes similar to KstD and KshAB of M. tuberculosis H37Rv by more than 35\% and, most likely, do not degrade steroids.

The thermophilic G. kaustophilus and P. thermoglucosidasius strains have been reported to provide separate reactions of steroid modification $[19,20]$. The BLAST search for more than 20 steroid catabolism enzymes (Supplementary Table S2) in these bacteria discovered the putative proteins that are $47 \%$ and $45 \%$ similar to the reference FadA5, respectively, and the $P$. thermoglucosidasius enzymes that are similar to HsaF and HsaE of M. tuberculosis H37Rv by $48 \%$ and $41 \%$, respectively (Supplementary Table S6). FadA5 is known additionally to be involved in fatty acid $\beta$-oxidation; thus, the corresponding proteins of G. kaustophilus and P. thermoglucosidasius may not be intended for steroid catabolism. HsaEF participate in oxidation of the hydroxydiene derivative of hexanoic acid, meaning that similar enzymes do not necessarily participate in the catabolism of steroid compounds.

\section{Conclusions}

The thermophilic strain Saccharopolyspora hirsuta VKM Ac- $666^{\mathrm{T}}$ is capable of transforming various steroids $[23,24]$. As confirmed in this study, the strain efficiently transforms cholesterol and 26-alcohols with both $3 \beta$-ol-5-ene and 3-keto-4-ene A-ring structures being key intermediates. The genes related to sterol metabolism and cholic acid catabolism were for the first time identified in the genome of this thermophilic strain. The organization of the steroid catabolism genes is generally similar to that in other actinobacteria, with some differences related to individual genes and their grouping. Future transcriptomic and proteomic studies are of significance for a clearer understanding of the peculiarities of steroid catabolism in thermophilic actinobacteria.

The presence of key enzymes responsible for steroid core disruption was identified only in seven of 52 thermophilic bacteria of various phylogenetic positions, thus suggesting that steroid-degrading activity is not common in the thermophilic species.

The results contribute to the knowledge on the diversity of microbial steroid degraders and the features of steroid catabolism by thermophilic actinobacteria and could be useful for application in pharmaceutical and environmental steroid biotechnology.

Supplementary Materials: The following are available online at https: / www.mdpi.com/article/ 10.3390/microorganisms9122554/s1, Supplementary Figures S1-S31: HPLC-, MS- and NMR- supplementary data, Supplementary Table S1: List of thermophilic and thermotolerant bacteria to be screened for the key genes of the steroid catabolic 9,10-seco-pathway, Supplementary Table S2: List of enzymes of steroid catabolism for BLAST+ search, Supplementary Table S3: Candidate genes 
for steroid or bile acid degradation in S. hirsuta VKM Ac- $666^{\mathrm{T}}$, Supplementary Table S4: List of homologous genes between S. hirsuta VKM Ac- $666^{\mathrm{T}}$, R. jostii RHA1, and M. tuberculosis H37Rv, Supplementary Table S5: List of actinobacterial strains with the similar proteins to the reference KshA, KshB, KstD of M. tuberculosis H37Rv, Supplementary Table S6: Result of BLAST search for 29 protein sequences of $M$. tuberculosis steroid catabolism enzymes in the Geobacillus kaustophilus HTA426 and Parageobacillus thermoglucosidasius DSM 2542 genomes.

Author Contributions: Conceptualization, T.L., V.F. and M.D.; methodology, T.L., V.F., A.S., S.T. and E.B.; validation, T.L., V.F., A.S. and A.K.; formal analysis, S.T. and E.B.; investigation, T.L., V.F., A.S., S.T., E.B. and A.K.; writing—original draft preparation T.L. and V.F.; writing—review and editing, T.L., V.F., A.S., S.T., E.B., A.K. and M.D.; visualization, T.L., V.F., S.T. and A.S.; project administration, M.D.; funding acquisition, M.D. All authors have read and agreed to the published version of the manuscript.

Funding: This work was supported by the Russian Science Foundation under the Grant No. 21-64-00024.

Data Availability Statement: Not applicable.

Conflicts of Interest: The authors declare no conflict of interest in this work.

\section{References}

1. Bergstrand, L.H.; Cardenas, E.; Holert, J.; Van Hamme, J.D.; Mohn, W.W. Delineation of steroid-degrading microorganisms through comparative genomic analysis. mBio 2016, 7, e00166-16. [CrossRef]

2. Holert, J.; Cardenas, E.; Bergstrand, L.H.; Zaikova, E.; Hahn, A.S.; Hallam, S.J.; Mohn, W.W. Metagenomes reveal global distribution of bacterial steroid catabolism in natural, engineered, and host environments. mBio 2018, 9, e02345-17. [CrossRef] [PubMed]

3. Philipp, B. Bacterial degradation of bile salts. Appl. Microbiol. Biotechnol. 2011, 89, 903-915. [CrossRef]

4. Donova, M.V.; Egorova, O.V. Microbial steroid transformations: Current state and prospects. Appl. Microbiol. Biotechnol. 2012, 94, 1423-1447. [CrossRef]

5. Olivera, E.R.; Luengo, J.M. Steroids as environmental compounds recalcitrant to degradation: Genetic mechanisms of bacterial biodegradation pathways. Genes 2019, 10, 512. [CrossRef]

6. Giorgi, V.; Menéndez, P.; García-Carnelli, C. Microbial transformation of cholesterol: Reactions and practical aspects-An update. World J. Microbiol. Biotechnol. 2019, 35, 131. [CrossRef] [PubMed]

7. Griffin, J.E.; Gawronski, J.D.; Dejesus, M.A.; Ioerger, T.R.; Akerley, B.J.; Sassetti, C.M. High-resolution phenotypic profiling defines genes essential for mycobacterial growth and cholesterol catabolism. PLoS Pathog. 2011, 7, e1002251. [CrossRef] [PubMed]

8. Van der Geize, R.; Yam, K.; Heuser, T.; Wilbrink, M.H.; Hara, H.; Anderton, M.C.; Sim, E.; Dijkhuizen, L.; Davies, J.E.; Mohn, W.W.; et al. A gene cluster encoding cholesterol catabolism in a soil actinomycete provides insight into Mycobacterium tuberculosis survival in macrophages. Proc. Natl. Acad. Sci. USA 2007, 104, 1947-1952. [CrossRef] [PubMed]

9. McLeod, M.P.; Warren, R.L.; Hsiao, W.W.L.; Araki, N.; Myhre, M.; Fernandes, C.; Miyazawa, D.; Wong, W.; Lillquist, A.L.; Wang, D.; et al. The complete genome of Rhodococcus sp. RHA1 provides insights into a catabolic powerhouse. Proc. Natl. Acad. Sci. USA 2006, 103, 15582-15587. [CrossRef]

10. Uhía, I.; Galán, B.; Kendall, S.L.; Stoker, N.G.; García, J.L. Cholesterol metabolism in Mycobacterium smegmatis: Cholesterol pathway. Environ. Microbiol. Rep. 2012, 4, 168-182. [CrossRef]

11. Drzyzga, O.; de las Heras, L.F.; Morales, V.; Navarro Llorens, J.M.; Perera, J. Cholesterol degradation by Gordonia cholesterolivorans. Appl. Environ. Microbiol. 2011, 77, 4802-4810. [CrossRef] [PubMed]

12. Shtratnikova, V.Y.; Schelkunov, M.I.; Fokina, V.V.; Bragin, E.Y.; Lobastova, T.G.; Shutov, A.A.; Kazantsev, A.V.; Donova, M.V. Genome-wide transcriptome profiling provides insight on cholesterol and lithocholate degradation mechanisms in Nocardioides simplex VKM Ac-2033D. Genes 2020, 11, 1229. [CrossRef]

13. Mohn, W.W.; Wilbrink, M.H.; Casabon, I.; Stewart, G.R.; Liu, J.; van der Geize, R.; Eltis, L.D. Gene cluster encoding cholate catabolism in Rhodococcus spp. J. Bacteriol. 2012, 194, 6712-6719. [CrossRef]

14. Feller, F.M.; Holert, J.; Yücel, O.; Philipp, B. Degradation of bile acids by soil and water bacteria. Microorganisms 2021, 9, 1759. [CrossRef]

15. Barrientos, Á.; Merino, E.; Casabon, I.; Rodríguez, J.; Crowe, A.M.; Holert, J.; Philipp, B.; Eltis, L.D.; Olivera, E.R.; Luengo, J.M. Functional analyses of three acyl-CoA synthetases involved in bile acid degradation in Pseudomonas putida DOC21. Environ. Microbiol. 2015, 17, 47-63. [CrossRef] [PubMed]

16. Horinouchi, M.; Koshino, H.; Malon, M.; Hirota, H.; Hayashi, T. Steroid degradation in Comamonas testosteroni TA441: Identification of the entire $\beta$-oxidation cycle of the cleaved B ring. Appl. Environ. Microbiol. 2019, 85, e01204-19. [CrossRef] [PubMed]

17. Gallo, G.; Puopolo, R.; Carbonaro, M.; Maresca, E.; Fiorentino, G. Extremophiles, a nifty tool to face environmental pollution: From exploitation of metabolism to genome engineering. Int. J. Environ. Res. Public Health 2021, 18, 5228. [CrossRef]

18. Ishino, S.; Ishino, Y. DNA polymerases as useful reagents for biotechnology-the history of developmental research in the field. Front. Microbiol. 2014, 5, 465. [CrossRef] 
19. Sideso, O.; Williams, R.A.D.; Welch, S.G.; Smith, K.E. Progesterone 6-hydroxylation is catalysed by cytochrome P-450 in the moderate thermophile Bacillus thermoglucosidasius strain 12060. J. Steroid Biochem. Mol. Biol. 1998, 67, 163-169. [CrossRef]

20. Al-Tamimi, S.; Al-Awadi, S.; Oommen, S.; Afzal, M. Modification of progesterone and testosterone by a food-borne thermophile Geobacillus kaustophilus. Int. J. Food Sci. Nutr. 2010, 61, 78-86. [CrossRef] [PubMed]

21. Sodano, G.; Trabucco, A.; De Rosa, M.; Gambacorta, A. Microbiological reduction of steroidal ketones using the thermophilic bacterium Caldariella acidophila. Experientia 1982, 38, 1311-1312. [CrossRef]

22. Lacey, J.; Goodfellow, M.J. A novel actinomycete from sugar-cane bagasse: Saccharopolyspora hirsuta gen. et. sp. nov. J. Gen. Microbiol. 1975, 88, 75-85. [CrossRef] [PubMed]

23. Kollerov, V.V.; Monti, D.; Deshcherevskaya, N.O.; Lobastova, T.G.; Ferrandi, E.E.; Larovere, A.; Gulevskaya, S.A.; Riva, S.; Donova, M.V. Hydroxylation of lithocholic acid by selected actinobacteria and filamentous fungi. Steroids 2013, 78, 370-378. [CrossRef] [PubMed]

24. Lobastova, T.G.; Khomutov, S.M.; Shutov, A.A.; Donova, M.V. Microbiological synthesis of stereoisomeric $7(\alpha / \beta)-$ hydroxytestololactones and 7( $\alpha / \beta)$-hydroxytestolactones. Appl. Microbiol. Biotechnol. 2019, 103, 4967-4976. [CrossRef] [PubMed]

25. Lobastova, T.G.; Fokina, V.V.; Bragin, E.Y.; Shtratnikova, V.Y.; Starodumova, I.P.; Tarlachkov, S.V.; Donova, M.V. Draft genome sequence of the moderately thermophilic actinobacterial steroid-transforming Saccharopolyspora hirsuta subsp. hirsuta strain VKM Ac-666T. Microbiol. Resour. Announc. 2020, 9, e01327-19. [CrossRef]

26. Park, N.S.; Myeong, J.S.; Park, H.J.; Han, K.B.; Kim, S.N.; Kim, E.S. Characterization and culture optimization of regiospecific cyclosporin hydroxylation in rare actinomycetes species. J. Microbiol. Biotechnol. 2005, 15, 188-191.

27. Jork, H.; Funk, W.; Fischer, W.; Wimmer, H. Thin-Layer Chromatography. Reagents and Detection Methods. Physical and Chemical Detection Methods: Fundamentals, Reagents I; VCH: Weinheim, Germany, 1990; Volume 1a, pp. 333-336.

28. Tatusova, T.; DiCuccio, M.; Badretdin, A.; Chetvernin, V.; Nawrocki, E.P.; Zaslavsky, L.; Lomsadze, A.; Pruitt, K.D.; Borodovsky, M.; Ostell, J. NCBI prokaryotic genome annotation pipeline. Nucleic Acids Res. 2016, 44, 6614-6624. [CrossRef]

29. Aziz, R.K.; Bartels, D.; Best, A.A.; Dejongh, M.; Disz, T. The RAST server: Rapid annotations using subsystems technology. BMC Genom. 2008, 9, 75. [CrossRef]

30. Overbeek, R.; Olson, R.; Pusch, G.D.; Olsen, G.J.; Davis, J.J.; Disz, T.; Edwards, R.A.; Gerdes, S.; Parrello, B.; Shukla, M.; et al. The SEED and the rapid annotation of microbial genomes using subsystems technology (RAST). Nucleic Acids Res. 2014, 42, D206-D214. [CrossRef]

31. Moriya, Y.; Itoh, M.; Okuda, S.; Yoshizawa, A.C.; Kanehisa, M. KAAS: An automatic genome annotation and pathway reconstruction server. Nucleic Acids Res. 2007, 35, W182-W185. [CrossRef]

32. Emms, D.M.; Kelly, S. OrthoFinder: Solving fundamental biases in whole genome comparisons dramatically improves orthogroup inference accuracy. Genome Biol. 2015, 16, 157. [CrossRef] [PubMed]

33. Emms, D.M.; Kelly, S. OrthoFinder: Phylogenetic orthology inference for comparative genomics. Genome Biol. 2019, $20,238$. [CrossRef] [PubMed]

34. Altschul, S.F.; Gish, W.; Miller, W.; Myers, E.W.; Lipman, D.J. Basic local alignment search tool. J. Mol. Biol. 1990, 215, 403-410. [CrossRef]

35. Kumar, S.; Stecher, G.; Tamura, K. MEGA7: Molecular evolutionary genetics analysis version 7.0 for bigger datasets. Mol. Biol. Evol. 2016, 33, 1870-1874. [CrossRef]

36. Camacho, C.; Coulouris, G.; Avagyan, V.; Ma, N.; Papadopoulos, J.; Bealer, K.; Madden, T.L. BLAST+: Architecture and applications. BMC Bioinform. 2009, 10, 421. [CrossRef]

37. Shivlata, L.; Satyanarayana, T. Thermophilic and alkaliphilic Actinobacteria: Biology and potential applications. Front. Microbiol. 2015, 6, 1014. [CrossRef]

38. Nesbitt, N.M.; Yang, X.; Fontán, P.; Kolesnikova, I.; Smith, I.; Sampson, N.S.; Dubnau, E. A thiolase of Mycobacterium tuberculosis is required for virulence and production of androstenedione and androstadienedione from cholesterol. Infect. Immun. 2010, 78, 275-282. [CrossRef] [PubMed]

39. Thomas, S.T.; VanderVen, B.C.; Sherman, D.R.; Russell, D.G.; Sampson, N.S. Pathway profiling in Mycobacterium tuberculosis: Elucidation of cholesterol-derived catabolite and enzymes that catalyze its metabolism. J. Biol. Chem. 2011, 286, 43668-43678. [CrossRef]

40. Carere, J.; McKenna, S.E.; Kimber, M.S.; Seah, S.Y.K. Characterization of an aldolase-dehydrogenase complex from the cholesterol degradation pathway of Mycobacterium tuberculosis. Biochemistry 2013, 52, 3502-3511. [CrossRef] [PubMed]

41. Casabon, I.; Crowe, A.M.; Liu, J.; Eltis, L.D. FadD3 is an acyl-CoA synthetase that initiates catabolism of cholesterol rings C and D in actinobacteria: Role of FadD3 in cholesterol catabolism. Mol. Microbiol. 2013, 87, 269-283. [CrossRef]

42. Yang, M.; Lu, R.; Guja, K.E.; Wipperman, M.F.; St. Clair, J.R.; Bonds, A.C.; Garcia-Diaz, M.; Sampson, N.S. Unraveling cholesterol catabolism in Mycobacterium tuberculosis: ChsE4-ChsE5 $\alpha 2 \beta 2$ acyl-CoA dehydrogenase initiates $\beta$-oxidation of 3-oxo-cholest-4-en26-oyl CoA. ACS Infect. Dis. 2015, 1, 110-125. [CrossRef]

43. Crowe, A.M.; Casabon, I.; Brown, K.L.; Liu, J.; Lian, J.; Rogalski, J.C.; Hurst, T.E.; Snieckus, V.; Foster, L.J.; Eltis, L.D. Catabolism of the last two steroid rings in Mycobacterium tuberculosis and other bacteria. mBio 2017, 8, e00321-17. [CrossRef] [PubMed]

44. Gadbery, J.E.; Round, J.W.; Yuan, T.; Wipperman, M.F.; Story, K.T.; Crowe, A.M.; Casabon, I.; Liu, J.; Yang, X.; Eltis, L.D.; et al. IpdE1-IpdE2 is a heterotetrameric acyl coenzyme A dehydrogenase that is widely distributed in steroid-degrading bacteria. Biochemistry 2020, 59, 1113-1123. [CrossRef] 
45. Shtratnikova, V.Y.; Schelkunov, M.I.; Fokina, V.V.; Bragin, E.Y.; Shutov, A.A.; Donova, M.V. Different genome-wide transcriptome responses of Nocardioides simplex VKM Ac-2033D to phytosterol and cortisone 21-acetate. BMC Biotechnol. 2021, $21,7$. [CrossRef] [PubMed]

46. Yuan, T.; Werman, J.M.; Yin, X.; Yang, M.; Garcia-Diaz, M.; Sampson, N.S. Enzymatic $\beta$-oxidation of the cholesterol side chain in Mycobacterium tuberculosis bifurcates stereospecifically at hydration of 3-oxo-cholest-4,22-dien-24-oyl-CoA. ACS Infect. Dis. 2021, 7, 1739-1751. [CrossRef]

47. Smith, K.E.; Williams, R.A.D.; Sideso, O. Transformation of progesterone by a thermophilic bacillus. FEMS Microbiol. Lett. 1992, 92, 29-34. [CrossRef]

48. Donova, M.V. Transformation of steroids by actinobacteria: A review. Appl. Biochem. Microbiol. 2007, 43, 1-14. [CrossRef]

49. Yam, K.C.; D’Angelo, I.; Kalscheuer, R.; Zhu, H.; Wang, J.-X.; Snieckus, V.; Ly, L.H.; Converse, P.J.; Jacobs, W.R., Jr.; Strynadka, N.; et al. Studies of a ring cleaving dioxygenase illuminate the role of cholesterol metabolism in the pathogenesis of Mycobacterium tuberculosis. PLoS Pathog. 2009, 5, e1000344. [CrossRef]

50. Rosłoniec, K.Z.; Wilbrink, M.H.; Capyk, J.K.; Mohn, W.W.; Ostendorf, M.; van der Geize, R.; Dijkhuizen, L.; Eltis, L.D. Cytochrome P450 125 (CYP125) catalyses C26-hydroxylation to initiate sterol side-chain degradation in Rhodococcus jostii RHA1. Mol. Microbiol. 2009, 74, 1031-1043. [CrossRef]

51. Kreit, J. Microbial catabolism of sterols: Focus on the enzymes that transform the sterol 3-hydroxy-5-en into 3-keto-4-en. FEMS Microbiol. Lett. 2017, 364, fnx007. [CrossRef]

52. Capyk, J.K.; Kalscheuer, R.; Stewart, G.R.; Liu, J.; Kwon, H.; Zhao, R.; Okamoto, S.; Jacobs, R.W., Jr.; Eltis, L.D.; Mohn, W.W. Mycobacterial cytochrome P450 125 (Cyp125) catalyzes the terminal hydroxylation of C27 steroids. J. Biol. Chem. 2009, 284, 35534-35542. [CrossRef] [PubMed]

53. Ouellet, H.; Guan, S.; Johnston, J.B.; Chow, E.D.; Kells, P.M.; Burlingame, A.L.; Cox, J.S.; Podust, L.M.; Ortiz de Montellano, P.R. Mycobacterium tuberculosis CYP125A1, a steroid C27 monooxygenase that detoxifies intracellularly generated cholest-4-en-3-one: CYP125A1 in cholesterol metabolism. Mol. Microbiol. 2010, 77, 730-742. [CrossRef] [PubMed]

54. Casabon, I.; Swain, K.; Crowe, A.M.; Eltis, L.D.; Mohn, W.W. Actinobacterial acyl coenzyme A synthetases involved in steroid side-chain catabolism. J. Bacteriol. 2014, 196, 579-587. [CrossRef]

55. Wilbrink, M.H.; van der Geize, R.; Dijkhuizen, L. Molecular characterization of ltp3 and ltp4, essential for C24-branched chain sterol-side-chain degradation in Rhodococcus rhodochrous DSM 43269. Microbiology 2012, 158, 3054-3062. [CrossRef] [PubMed]

56. Bonds, A.C.; Yuan, T.; Werman, J.M.; Jang, J.; Lu, R.; Nesbitt, N.M.; Garcia-Diaz, M.; Sampson, N.S. Post-translational succinylation of Mycobacterium tuberculosis enoyl-CoA hydratase EchA19 slows catalytic hydration of cholesterol catabolite 3-oxo-chol-4,22diene-24-oyl-CoA. ACS Infect. Dis. 2020, 6, 2214-2224. [CrossRef]

57. Xu, L.-Q.; Liu, Y.-J.; Yao, K.; Liu, H.-H.; Tao, X.-Y.; Wang, F.-Q.; Wei, D.-Z. Unraveling and engineering the production of 23,24-bisnorcholenic steroids in sterol metabolism. Sci. Rep. 2016, 6, 21928. [CrossRef] [PubMed]

58. Schaefer, C.M.; Lu, R.; Nesbitt, N.M.; Schiebel, J.; Sampson, N.S.; Kisker, C. FadA5 a thiolase from Mycobacterium tuberculosis: A steroid-binding pocket reveals the potential for drug development against tuberculosis. Structure 2015, 23, 21-33. [CrossRef]

59. Aggett, R.; Mallette, E.; Gilbert, S.E.; Vachon, M.A.; Schroeter, K.L.; Kimber, M.S.; Seah, S.Y.K. The steroid side-chain-cleaving aldolase Ltp2-ChsH2DUF35 is a thiolase superfamily member with a radically repurposed active site. J. Biol. Chem. 2019, 294, 11934-11943. [CrossRef]

60. Itagaki, E.; Matushita, H.; Hatta, T. Steroid transhydrogenase activity of 3-ketosteroid- $\Delta^{1}$-dehydrogenase from Nocardia corallina. J. Biochem. 1990, 108, 122-127. [CrossRef]

61. Bragin, E.Y.; Shtratnikova, V.Y.; Dovbnya, D.V.; Schelkunov, M.I.; Pekov, Y.A.; Malakho, S.G.; Egorova, O.V.; Ivashina, T.V.; Sokolov, S.L.; Ashapkin, V.V.; et al. Comparative analysis of genes encoding key steroid core oxidation enzymes in fast-growing Mycobacterium spp. strains. J. Steroid Biochem. Mol. Biol. 2013, 138, 41-53. [CrossRef]

62. Zhang, Q.; Ren, Y.; He, J.; Cheng, S.; Yuan, J.; Ge, F.; Li, W.; Zhang, Y.; Xie, G. Multiplicity of 3-ketosteroid $\Delta^{1}$ dehydrogenase enzymes in Gordonia neofelifaecis NRRL B-59395 with preferences for different steroids. Ann. Microbiol. 2015, 65, 1961-1971. [CrossRef]

63. Shtratnikova, V.Y.; Schelkunov, M.I.; Fokina, V.V.; Pekov, Y.A.; Ivashina, T.; Donova, M.V. Genome-wide bioinformatics analysis of steroid metabolism associated genes in Nocardioides simplex VKM Ac-2033D. Curr. Genet. 2016, 62, 643-656. [CrossRef]

64. Guevara, G.; Fernández de las Heras, L.; Perera, J.; Navarro Llorens, J.M. Functional differentiation of 3-ketosteroid $\Delta^{1}$ dehydrogenase isozymes in Rhodococcus ruber strain Chol-4. Microb. Cell Factories 2017, 16, 42. [CrossRef] [PubMed]

65. Zhang, R.; Liu, X.; Wang, Y.; Han, Y.; Sun, J.; Shi, J.; Zhang, B. Identification, function, and application of 3-ketosteroid $\Delta^{1}-$ dehydrogenase isozymes in Mycobacterium neoaurum DSM 1381 for the production of steroidic synthons. Microb. Cell Factories 2018, 17, 77. [CrossRef] [PubMed]

66. Capyk, J.K.; D'Angelo, I.; Strynadka, N.C.; Eltis, L.D. Characterization of 3-ketosteroid $9 \alpha$-hydroxylase, a Rieske oxygenase in the cholesterol degradation pathway of Mycobacterium tuberculosis. J. Biol. Chem. 2009, 284, 9937-9946. [CrossRef]

67. Bragin, E.Y.; Shtratnikova, V.Y.; Schelkunov, M.I.; Dovbnya, D.V.; Donova, M.V. Genome-wide response on phytosterol in 9-hydroxyandrostenedione-producing strain of Mycobacterium sp. VKM Ac-1817D. BMC Biotechnol. 2019, 19, 39. [CrossRef] [PubMed]

68. Petrusma, M.; Hessels, G.; Dijkhuizen, L.; van der Geize, R. Multiplicity of 3-ketosteroid-9 $\alpha$-hydroxylase enzymes in Rhodococcus rhodochrous DSM43269 for specific degradation of different classes of steroids. J. Bacteriol. 2011, 193, 3931-3940. [CrossRef] 
69. Costa, S.; Giovannini, P.P.; Fantin, G.; Medici, A.; Pedrini, P. New 9,10-secosteroids from biotransformations of hyodeoxycholic acid with Rhodococcus spp. Helv. Chim. Acta 2013, 96, 1062. [CrossRef]

70. Costa, S.; Giovannini, P.P.; Fantin, G.; Medici, A.; Pedrini, P. New 9,10-Secosteroids from biotransformations of bile acids with Rhodococcus ruber. Helv. Chim. Acta 2013, 96, 2124. [CrossRef]

71. García, J.L.; Uhía, I.; Galán, B. Catabolism and biotechnological applications of cholesterol degrading bacteria: Cholesterol degradation. Microb. Biotechnol. 2012, 5, 679-699. [CrossRef]

72. Dresen, C.; Lin, L.Y.-C.; D'Angelo, I.; Tocheva, E.I.; Strynadka, N.; Eltis, L.D. A Flavindependent monooxygenase from Mycobacterium tuberculosis involved in cholesterol catabolism. J. Biol. Chem. 2010, 285, 22264-22275. [CrossRef] [PubMed] 